\title{
LOS NOMBRES PROPIOS: ¿LEXEMAS O MORFEMAS?
}

\author{
Francisco Osuna García \\ Universidad de Córdoba
}

La disyunción que se recoge en el título de este trabajo no es indispensable para una reflexión sobre los nombres propios. De la misma manera que no lo es para el estudio de cualquier otro tipo de signos, pues hay otras formas posibles de clasificar los datos lingüísticos, que, de carácter binario o no, tratan de establecer categorías, o clases, con las diferentes unidades significativas que utilizamos al hablar. Por el contrario, sí creemos que es indispensable el proyecto clasificador mismo, que nos debe llevar a agrupar en una clase todos aquellos signos que tienen las mismas características.

Todo proyecto clasificador implica unos criterios mediante los cuales se organiza el material objeto de estudio, en nuestro caso, el material lingüístico. Naturalmente los criterios seguidos deben aplicarse con coherencia. A priori, los criterios pueden ser diferentes; y los resultados también serán diferentes. Por este motivo, señalábamos que la disyunción planteada en el título es sólo uno de los posibles puntos de vista que se podrían seguir en el estudio de cualquier tipo de signos. Se podría haber planteado, por ejemplo, mediante la disyunción en palabras lienas o palabras vacías. Si no lo hemos hecho así, tratándose de formas lingüísticas, es porque creemos preferible hablar de signos frente a palabras y porque, en numerosos trabajos de la lingüística reciente, se parte de esta primera distinción en lexemas y morfemas para clasificar las formas lingüísticas.

Este tipo de clasificaciones binarias tiene, por otra parte, la ventaja de que nos lleva a una organización jerárquica de las clases, pues se procede estableciendo clases muy generales, que posteriormente se subdividen en subclases que comparten las características de la clase y tienen algún rasgo que las diferencia. Este procedimiento es preferible, en nuestra opinión, a las tradicionales partes de la oración que, en algunas de sus cristalizaciones más conocidas, establecen ocho o nueve clases de palabras paralelas, sin ningún tipo de relación jerárquica entre ellas.

RFE, LXXXIII, 2003, 1. $.^{\circ}-2 .{ }^{\circ}$, págs. 93-132 
Si la clasificación del material lingǘstico en lexemas y morfemas no ha sido más fecunda, quizás sea debido a que el criterio seguido para su definición se ha visto distorsionado por diferentes conceptos de significado que, en conjunto, podemos calificar de poco técnicos. La definición de lexemas y morfemas que considera a los primeros un conjunto abierto y a los segundos, un conjunto cerrado, nos parece poco adecuada, pues, en definitiva, no señala cuál es la función semántica de ambas categorías.

La definición de léxico de E. Coseriu, en cambio, nos parece mejor orientada:

Por léxico hay que entender la totalidad de aquellas palabras de una lengua que corresponden a la organización inmediata de la realidad extralinguiística. Al léxico, en este sentido, no pertenecen, pues, todas las palabras de una lengua, sino sólo aquellas que en la lengua están por la realidad misma nombrada mediante el lenguaje'.

Pero, al clasificar las palabras en lexemáticas, categoremáticas y morfemáticas, no aparecen los nombres propios entre los ejemplos utilizados para explicar los diferentes tipos. De manera sintomática, el mismo E. Coseriu señala que estas tres categorías de palabras tienen algunas dificultades:

En realidad, las palabras morfemáticas se oponen como clase de palabras a las otras dos clases (palabras lexemáticas y categoremáticas); y las categorías verbales (sustantivo, adjetivo, verbo y adverbio) corresponden a una distinción que se entrecruza con la distinción entre palabras lexemáticas y categoremáticas ${ }^{2}$.

Y, también de manera sintomática, cuando trata del plural de los nombres propios, no aparece la cuestión de la categoría a la que pertenecen, sólo nos dice que «no son nombres de clase» ${ }^{3}$.

La caracterización que demos de los nombres propios determinará la categoría en la que deban incluirse 0 , a la inversa, la categoría en la que los incluyamos dependerá de la caracterización que demos de ellos. Aunque son dos aspectos de una misma cuestión, los trataremos por separado: veremos en primer lugar en qué categorías se los ha incluido o con qué categorías se los ha relacionado; en segundo lugar, trataremos de las diferentes caracterizaciones que se han dado de ellos; finalmente presentaremos lo que, en nuestra opinión, podemos llamar la semántica y la sintaxis de los nombres propios, explicando, por

\footnotetext{
' E. Coseriu, Gramática, Semántica, Universales, Madrid, Gredos, 1978, pág. 133. En E. Coseriu, Principios de semántica estructural, Madrid, Gredos, 1977, identifica la función léxica con «la estructuración primaria de la experiencia por medio de palabras», pág. 88.

${ }^{2}$ E. Coseriu, Gramática, pág. 134.

${ }^{3}$ E. Coseriu, Teoria del lenguaje y lingüística general, Madrid, Gredos, 1973, pág. 268.
} 
un lado, la clase a la que pertenecen y, por otro, las combinaciones sintácticas en las que se insertan.

\section{DIFERENTES PROPUESTAS CLASIFICADORAS}

La preocupación lingüística por el estudio de los nombres propios se ha desarrollado en parte impulsada por los estudios de lógica y de filosofía. En este ámbito no se pretende establecer una clasificación de los signos lingüísticos; y, en este sentido, las clasificaciones establecidas no son aplicables en su totalidad al material lingüistico; pero, en la medida en que los nombres propios son objeto de reflexión, su análisis puede ayudar a entender mejor la función de este tipo de signos.

Las clasificaciones de los modos de referir de lógicos y filósofos no son, en algunos casos, clasificaciones de formas lingüísticas. Ch. Morris, entre los modos de significar, distingue tres tipos de indetificadores:

Los indizadores son señales fuera del lenguaje. Sirvan como ejemplo el gesto de señalar y la veleta [...]. Los descriptores identificadores que describen una locación [...]. Los nominadores son identificadores y a la vez símbolos del lenguaje, y signos de sustitutos, por lo tanto como sinónimos de otros identificadores [...]. Son asimismo nominadores términos como kello», «esto», «yo», «ahora» y signos singulares como los nombres propios ${ }^{4}$.

A los lógicos les interesan las expresiones en su función referencial o designativa, sean signos o construcciones. Por este motivo, E. Husserl, después de explicar la forma en que nos referimos a la realidad con esto, añade que este tipo de expresiones «tendrían, según esto, una gran analogía con los nombres propios, cuando estos últimos funcionan con su significado propio. También el nombre propio nombra directamente el objeto» ${ }^{5}$, aunque señala alguna diferencia entre ellos.

La clasificación de lo que P. F. Strawson llama expresiones con «uso referencial singularizador» abarca exclusivamente material lingüístico:

las clases de expresiones más comúnmente usadas de este modo son: pronombres demostrativos en singular («éste» y «ése»), nombre propios (por ejemplo, «Venecia», «Napoleón», «Juan»), pronombres personales e impersonales en singular («él», «ella», «yo», «tú», «ello») y frases que comienzan con el artículo determinado seguidas de un sustantivo, adjetivado o no, en singular (por ejemplo, «la mesa», «el hombre viejo», «el rey de Francia») ${ }^{6}$.

\footnotetext{
${ }^{4}$ Ch. Morris, Signos, lenguaje y conducta, Buenos Aires, Losada, 1962, pág. 90.

${ }^{5}$ E. Husserl, Investigaciones lógicas, Madrid, Revista de Occidente, 1976, pág. 613.

${ }^{6}$ P. F. Strawson, «Sobre el referir», en L. MI. Valdés Villanueva (ed.), La buisqueda del significado, Madrid, Tecnos, 1971, págs. 36-86, pág. 57.
} 
Como decíamos, las clasificaciones de lógicos y filósofos nos interesan ya que atribuyen una función semántica a los nombres propios, que, en la medida en que coincida con el uso, debería ser tenida en cuenta por los lingüistas. Esto no significa aceptar, siguiendo a G. Frege por ejemplo, que en lingüística todo uso referencial singularizador es un nombre propio, ni considerar, siguiendo a B. Russell, que los auténticos nombres propios son los demostrativos. Tampoco supone identificar nombres propios, pronombres y descripciones definidas, pues, como señala el mismo Strawson, las expresiones que tienen un uso referente difieren entre ellas de tres maneras: en su mayor o menor dependencia del contexto, en el mayor o menor significado descriptivo que poseen, $y$ en el hecho de que su uso esté regulado por convenciones generales o por convenciones ad hoc, que sería el caso de los nombres propios.

Así pues, desde la filosofía y desde la lógica, los nombres propios se sitúan entre las expresiones referenciales que tienen una función designativa, que es semejante, aunque no idéntica, a la que desempeñan otros signos, como los pronombres, $\mathbf{u}$ otras construcciones, como la combinación de artículo determinado con un elemento léxico. Atendiendo, pues, al tipo de relación que se establece entre el nombre propio y la realidad extralingüística, estamos ante una relación diferente de la que se establece entre los signos léxicos y esa misma realidad extralinguística.

Esta caracterización del nombre propio como perteneciente a la misma categoría que las descripciones definidas o los pronombres aparece recogida también en la linguística. Nos referimos sólo a dos ejemplos. Robert M. Martin afirma taxativamente que «Definite descriptions and proper names are both singular terms, that is, they refer (if at all) to exactly one thing» ${ }^{7}$. Y E. Alarcos ${ }^{8}$, de forma algo escéptica, afirma que de entre los sustantivos se suele segregar una especie conocida como nombres propios, pero que en realidad designan objetos únicos; con lo cual el artículo, en el sentido de Frege, lo que hace es transformar los sustantivos en nombres propios, ya que los convierte de clasificadores en identificadores. Como vemos, E. Alarcos sigue la tradición de incluir los nombre propios entre los sustantivos, pero reconoce que su función semántica no es la de un sustantivo sino la de la construcción artículo más sustantivo.

Sin embargo, al explicar la función semántica de los nombres propios, parece que hay una cierta preferencia por hacerlo realzando sus semejanzas funcionales con los pronombres deícticos.

Esta semejanza con los pronombres se expresa a veces de manera indirecta,

' Robert M. Martin, The Meaning of Language, Massachusetts, The MIT Press, 1993, pág. 133.

${ }^{8}$ E. Alarcos, Gramática de la lengua española, Madrid, Espasa-Calpe, 1994, págs. 68-69. 
es decir, se incluyen los nombres propios entre los sustantivos o nombres; pero, al tratar de los pronombres, se explican por su equivalencia con los nombres propios. Uno de los casos más claros de esta explicación lo encontramos ya en la primera gramática de la lengua española. Para Nebrija, la calidad es uno de los seis accidentes del nombre,

calidad es aquello por lo que el nombre común se distingue del proprio. Proprio nombre es aquel que conviene a uno solo, como César, Pompeio. Común nombre es aquel que conviene a muchos particulares, que los latinos llaman apelativo, como ombre es común a "César' y 'Pompeio'.

Hasta aquí una caracterización que se repetirá en términos semejantes en muchas ocasiones. Sin embargo, en el capítulo dedicado al pronombre afirma que «llárnase pronombre porque se pone en lugar de nombre proprio; porque tanto vale io como Antonio, tú como Hernando» ${ }^{10}$.

Esta identificación del nombre propio con los pronombres la encontramos de manera reiterada en las primeras gramáticas de nuestra lengua. De manera semejante a como hemos visto en Nebrija, Villalón afirma que

pronombre es una dicción o vocablo castellano que se pone en lugar del nombre propio. Como estos vocablos, yo, tú, aquel. Estos vocablos y semejantes por sí ninguna cosa significan más de aquella que mostraren, o fuera la intención del que la pronuncia señalar o mostrar o entender por ella. Y usamos de estos vocablos en lugar de Pedro, Juan, Martín, que son nombres propios de particulares hombres que demostramos o entendemos demostrar hablando ".

Esta asimilación de los nombres propios a los pronombres la encontramos también en la lingüística actual, y aparece en estudios de muy diferente orientación.

S. Fernández Ramírez ${ }^{12}$, después de referirse a la interpretación de los nombres propios que los sitúa en el campo simbólico del lenguaje, afirma que otros deben ser los puntos de vista de Hjelmslev cuando alude a la posibilidad de considerar el nombre propio como una subcategoria de los pronombres, sin entrar en más detalles. Digamos, antes de continuar, que nuestra reflexión sobre los nombres propios va orientada en la dirección sugerida por Hjelmslev,

\footnotetext{
9 A. de Nebrija, Gramática de la lengua castellana, ed. de A. Quilis, Madrid, Centro de Estudios Ramón Areces, 1990, pág. 176.

${ }^{10}$ Ibid., pág. 192.

${ }^{11}$ Cristóbal de Villalón, Gramática castellana, ed. de Constantino García, Madrid, C.S.I.C., 1971, pág. 34.

12 S. Fernández Ramírez, Gramática española I. Prolegómenos, ed. de J. Polo, Madrid, Arco/Libros, 1985, págs. 280-281.
} 
pues trataremos de justificar su caracterización como una subclase de los deícticos.

Robert M. Martin, en el capítulo dedicado a los signos deícticos incluye un apartado sobre «Indexicals and Proper Names», en el que leemos que «indexicals work somewhat similarly to proper names» ${ }^{13}$. La función de ambos es señalar (pointing). Y, de manera semejante, Timothy $C$. Potts propone utilizar el término inglés pointers frente al término griego deicticos; y considera que "proper names, in a sense, replace pointers, in special cases" 14 .

M. Lluisa Hernanz y J. M. ${ }^{a}$ Brucart consideran que los nombres propios son unidades exclusivamente denotativas o nombradoras y señalan como una de sus características el hecho de que «suelen aparecer como única realización de su SN. En este último aspecto se asemejan más a los pronombres que a los nombres comunes» ${ }^{15}$, aunque reconocen que en algunas circunstancias los nombres propios pueden llevar complementos y determinantes.

En estudios monográficos sobre el nombre propio, también encontramos caracterizaciones semejantes. Jean Molino, después de exponer una especie de tipología de los nombres propios, explica que todos ellos pueden agruparse «autour de trois pôles qui correspondent exactement aux trois dimensions de la deixis». Estas tres dimensiones de la deixis son yo, aquí y ahora. Por lo tanto, «les noms propres se constituent ainsi parallèlement aux diverses catégories déictiques (ou embrayeurs): ainsi se manifeste l'unité du champ déictique du langue auquel appartiennent noms propres et déictiques» ${ }^{16}$.

Esta asimilación de los nombres propios a los deícticos se realiza a veces mediante su equiparación con un tipo particular de deícticos, los pronombres personales. Estamos ante una cuestión importante, que sólo podremos aclarar observando el uso que hacemos de ambas formas. Para M. A. K. Halliday,

personal pronouns and proper names are alike in that, for both, the reference is typically unique. With pronouns, the referent is defined interpersonally, by the speech situatio, with proper names it is defined experientially: there exists only one, at least in the relevant boy of experiences ${ }^{17}$.

$\mathrm{Y}$, desde otro planteamiento diferente, M.. Josep Cuenca y Joseph Hilferty afirman que

${ }_{13}$ Robert M. Martin, The Meaning,.., pág. 191.

14 Timothy C. Pots, Structures and Categories for the Representation of Meaning, Cambridge, University Press, 1994, pág. 211.

15 M." Lluisa Hernanz y J. M." Bricart, La sintaxis 1. Principios teóricos. La oración simple, Barcelona, Ed. Crítica, 1987, pág. 153.

16 J. Molino, «Le nom propre dans la langue», en Langages 66, 1982, págs. 5-20, pág. 7

${ }^{17}$ M. A. K. Halliday, An Introduction to Functional Grammar, London, Anold, 1989, pág. 168. 
de acuerdo con su comportamiento, deberíamos hablar de 'pronombre propio' más que de 'nombre propio'. El nombre propio comparte muchas características con los pronombres personales tónicos, con los que es intercambiable $[\ldots]$

No sucede así, en carnbio, con el nombre común, que no siempre puede ser sustituido por el pronombre personal y, en general, se retoma en el discurso mediante otros mecanismos. Además, tanto el nombre propio como el pronombre se comportan como sintagmas nominales completos, a diferencia del nombre común, que es característicamente el núcleo del sintagma nominal ${ }^{18}$.

Los testimonios que estamos recogiendo no pretenden ser una recopilación exhaustiva de todos los estudios sobre los nombres propios, ni presuponen que estemos de acuerdo con los rasgos atribuidos, sólo pretenden ser una muestra del amplio abanico de interpretaciones que se han dado de los nombre propios. En la última cita se recoge un planteamiento que sigue los puntos de vista de la lingüística cognitiva, de acuerdo con los cuales sólo el reconocimiento del carácter difuso de las categorías nos permitirá explicar correctamente su funcionamiento. En nuestra opinión, hay que admitir el carácter difuso de las categorías entendidas como las clasificaciones que las lenguas imponen a la realidad; pero no deberíamos admitir el carácter difuso para las categorías que la lingüística establece sobre el material linguístico. Entendemos que estas últimas, como las de cualquier estudio que tengan pretensiones científicas, deben estar bien definidas.

En esta aproximación a algunas caracterizaciones que relacionan los nombres propios con los pronombres deícticos, nos referimos finalmente a otro estudioso que, de nuevo desde el campo de la lógica, relaciona los nombres propios con los índices. Se trata de Ch. S. Peirce. Tenemos que reconocer que la teoría de Peirce no nos resulta demasiado clara y que se pueden rastrear en su obra afirmaciones que contradicen en alguna medida la inclusión de los nombres propios entre los índices: la que recogemos en segundo lugar es una muestra de ello. Por una parte, leemos lo siguiente: «Defino un Índice como un signo determinado por su objeto dinámico en virtud de estar en una relación real con éste. Tal es un Nombre Propio» ${ }^{19}$; pero más adelante precisa que

Subíndices o Hiposemas son signos que resultan tales principalmente por una conexión real con sus objetos. Así, un nombre propio, un pronombre personal demostrativo o un pronombre relativo, o la letra incluida en un diagrama, denota lo que efectivamente denota por una conexión real con su objeto, pero ninguno de ellos es un Índice porque no es un individuo ${ }^{20}$.

${ }^{18}$ M. J. Cuenca y J. Hilferty, Introducción a la lingüística cognitiva, Barcelona, Arjel, 1999, pág. 190.

${ }^{19}$ Ch. S. Peirce, Obra lógica-semiótica, Madrid, Taurus, 1987, pág. 118

20 lbid., pág. 265. 
y de nuevo leemos lo siguiente:

En cuanto a los nombres propios puede quizás haber una diferencia de opinión, especialmente si se toma como referencia las señales. Pero probablemente tengan que ser considerados Índices, ya que la conexión de hecho entre Instancias de las mismas palabras típicas con los mismos objetos es lo único (cuando oímos hablar) que hace que se los interprete como denotando objetos $^{21}$.

Esta inseguridad de las explicaciones de Peirce sobre los nombres propios está en clara correspondencia con las diferentes interpretaciones que hemos podido comprobar en los textos recogidos anteriomente.

Pero, según recoge Mary-Noëlle Gary-Prieur, las gramáticas suelen presentar al nombre propio «comme un cas particulier dans la catégorie des noms» ${ }^{22}$. A veces se utiliza el término nombre como denominación genérica, y otras veces se utiliza el término sustantivo. Ya vimos que, para Nebrija, la calidad es el accidente que permite distinguir el nombre común del propio, según que convenga a uno solo o a muchos particulares.

Esta asimilación del nombre propio a los sustantivos se produce frecuentemente viendo los nombres propios como una subclase de los sustantivos. En otros casos, como vimos en E. Alarcos, la inclusión de los nombres propios entre los sustantivos se realiza a pesar de que se reconoce que tienen una función semántica diferente. $Y$ también tenemos opiniones según las cuales, linguísticamente, es imposible trazar una línea de separación entre los nombres propios y los nombres comunes.

Antes de continuar, queremos aclarar que, en nuestra opinión ${ }^{23}$, para signos del tipo silla, mesa o ró, es preferible utilizar la denominación de sustantivo frente a la de nombre común, pues, como signos de la lengua, son palabras clasificadoras y no designativas, es decir, por sí mismas no funcionan como nombres. Además la utilización del término sustantivo frente a nombre nos evita el riesgo de emplear como término técnico una palabra, nombre, que, aunque la podemos considerar metalinguíística, pertenece a la lengua común; $y$, como tal, es una categoría difusa. En cambio, el término sustantivo es más adecuado para su utilización metalingüística, pues es un término de carácter casi exclusivamente técnico.

La consideración del nombre propio como una subclase de los sustantivos

${ }^{21}$ Ibid., pág. 381. El texto recogido en esta cita lo encontramos también en Ch. S. Peirce, La ciencia de la semiótica, Buenos Aires, Nueva Visión, 1974, pág. 72.

${ }^{22}$ Mary-Noëlle Gary-Prieur, Grammaire du nom propre, Paris, PUF, 1994, pág. 2

${ }^{23} \mathrm{~F}$. Osuna, Teoría y enseñanza de la gramática, Málaga, Ágora, 1996, págs. 67-68; y F. Osuna, Las funciones referenciales en el castellano como bases de una gramática constructiva, Granada, Universidad de Granada, 1991, pág. 81. 
representa, aunque se exponga con otros términos, un punto de vista muy similar al visto en Nebrija.

En la Gramática general y razonada de Port-Royal se afirma que

\begin{abstract}
tenemos dos clases de ideas: unas que representan una cosa singular como la idea que cada persona tiene de su padre, de su madre, de su perro [...], otras que nos representan muchas semejantes, a las cuales esta idea puede convenir igualmente, como la idea que tenemos de hombre o de caballo en general, etc. El hombre ha necesitado de distintos nombres para estos diferentes tipos de ideas y ha llamado nombres propios a los que convienen a las ideas singulares, como el nombre de Sócrates, que conviene a cierto filósofo llamado Sócrates, el nombre de Paris, que conviene a la ciudad de París; y nombres generales o apelativos a los que significan ideas comunes, como la palabra hombre, que conviene a todos los hombres en general; y lo mismo las palabras león, perro, caballo, etc. ${ }^{24}$
\end{abstract}

Esta interpretación de los nombres propiós, con diferentes matices, ha continuado hasta nuestros días; y se caracteriza, según hemos expuesto, por la consideración del nombre propio como una subclase del nombre. Recogemos sólo algunos testimonios que nos parecen especialmente significativos, ya por la relevancia de sus autores, ya por la recurrencia en la caracterización.

Para V. Salvá, «es nombre propio el que expresa la idea de un individuo determinado de cualquier especie, v. gr. Margarita [...]. Apelativo es el que abraza a todos los de la misma clase o especie, v. gr. mujer, monte, [...]» ${ }^{25}$.

Según A. Bello,

nombre propio es el que se le pone a una persona o cosa individual para distinguirla de las demás de su especie o familia, como Italia, Roma [...].

Por el contrario, nombre apelativo (llamado también general o genérico) es el que conviene a todos los individuos de una clase, especie o familia, significando su naturaleza o las cualidades de que gozan, como ciudad, rí, hombre, árbol, encina, flor, jazmín, blanco, negro 26 .

Naturalmente, los ejemplos de nombre apelativo se explican porque, para $\mathrm{A}$. Bello, los nombres propios son siempre sustantivos, pero los nombres apelativos pueden ser sustantivos o adjetivos.

L. Tesnière afirma que

los sustantivos particulares pueden ser clasificados por su extensión y por su comprension: los sustantivos propios son los que tienen menos extensión y

${ }^{24}$ A. Arnauld y Cl. Lancelot, Gramática general y razonada de Port-Royal. Seguida de la segunda parne de Logica, ed, de R. Morillo, Madrid, SGEL, 1980, pág. 57.

25 V. Salvá, Gramática de la lengua castellana, Valencia, Librería de Mallén, 1847, pág. 11.

${ }^{26}$ A. Bello, Gramática de la lengua castellana, Buenos Aires, Sopena, 1970, pág. 58. 
más comprensión; los sustantivos comunes tienen más extensión y menos comprensión; pero, evidentemente, los que tienen más extensión y menos comprensión son los sustantivos generales ${ }^{27}$.

La exposición de Tesnière, como toda su obra, resulta impecable en cuanto a la coherencia metodológica; pero entendemos que no es adecuada para explicar el significado de las formas lingüísticas entendiéndolo como función semántica de los signos.

La RAE $^{28}$ establece una clasificación entre los nombres en la que opone el nombre genérico al nombre propio: el primero «que también se llama apelativo o común, es el que conviene a todas las personas o cosas de una misma clase, como hombre, caballo, ciudad». El segundo «es el que se da a persona o cosa determinada, para distinguirlo de las demás de su especie o clase: v. gr. Antonion.

De manera semejante, R. Seco ${ }^{29}$ distinguió, entre los sustantivos concretos, las subclases de los comunes y los propios, aunque su clasificación difiere de la de la RAE en que incluye los genéricos y los de materia como una subclase de los comunes.

Curiosa, y diferente de las propuestas anteriores, es la que encontramos en M. Ariza. Después de recapitular las características morfosintácticas de los nombres propios, continúa así:
pues bien, hay otra clase de sustantivos que en gran parte coincide con lo que acabamos de decir: el nombre propio abstracto, que $1^{\circ}$ ) rehúye el artícu- lo indeterminado (salvo con valor ponderativo), $2^{\circ}$ ) en plural pasan a concre- tos, $3^{\circ}$ ) no suelen presentar alternancias genéricas [...].Dicho esto creo que se puede afirmar que las gramáticas no aciertan cuando dicen que el nombre se divide en común y propio y que el común a su vez se divide en concreto y abstracto, como tampoco acierta mi amigo Marcos Marín cuando divide el nombre concreto en común y propio. Por lo que hemos visto, el nombre se divide en concreto y en abstracto, y el abstracto en común y propio ${ }^{30}$.

Si exceptuamos la última cita, que podríamos considerar más bien atípica y extraña, todas las clasificaciones anteriores de los nombres propios como una subclase de los sustantivos parten, de una manera implícita o explícita, de una teoría del significado que oscila entre la teoría intensional y la teoría extensional. En cualquiera de los dos casos se está considerando que el significado es

27 L. Tesnière, Elementos de sintaxis estructural I, Madrid, Gredos, 1994, pág. 111.

${ }^{28}$ RAE, Gramática castellana, Madrid, sucesores de Hernando, 1920, pág. 12.

${ }^{29}$ R. Seco, Manual de gramática española, Madrid, Aguilar, 1971, pag. 11.

${ }^{30}$ M. Ariza, «¿Es propio el nombre propio?», en E. R. Alcaide, M. del M. Ramos y F. Salguero (eds.), Estudios lingǘsticos en torno a la palabra, Sevilla, Universidad de Sevilla, 1993, págs. 33-40, pág. 40 . 
un objeto mental (intensión) o extralingüístico (extensión). En el primer supuesto, se suele justificar la diferencia entre sustantivos y nombres propios contraponiendo las ideas particulares a las ideas generales; en el segundo supuesto, se suele justificar la diferencia afirmando que el sustantivo conviene a muchos y el nombre propio conviene a uno solo. Pero, en ambos casos, estamos ante la misma categoría, ya que ambos tipos, sustantivos y nombres propios, comparten un mismo tipo de significado. Trataremos de mostrar que sustantivos y nombres propios no pueden incluirse en la misma categoría si entendemos que el significado es la función semántica, o el uso que hacemos de los signos, pues, al fin y al cabo, el uso que hacemos de un signo es aquello que lo caracteriza.

También tenemos numerosos estudios gramaticales en los que, como en los ya citados, los nombres propios son considerados como una subclase de los sustantivos, o de los nombres; pero la explicación que se da difiere claramente de las hasta ahora vistas y se pone de relieve que la función semántica del nombre propio es distinta de la función semántica de los sustantivos. De aquí podemos deducir que se tiene una idea clara de las diferencias entre ambas categorías, aunque, por razones pedagógicas o por el peso de la tradición, aparezcan los nombres propios incluidos en la clase de los sustantivos. Esta es la explicación que vimos en E. Alarcos.

Un ejemplo muy claro de esta interpretación lo encontramos también en A. Alonso y P. Henríquez Ureña, para quienes

\begin{abstract}
el nombre propio y el común se diferencian por el modo de designar la persona o cosa que nombran. El nombre común río, hombre, mujer [...], la designa refiriéndose a sus cualidades propias: río consiste en un modo determinado de ser la realidad [...]

En cambio, el nombre propio designa a la persona o cosa, como un simple distintivo individual sin alusion a sus cualidades. Una ciudad se llama Córdoba o Santiago, un hombre se llama Juan o Luis. Pero el nombre Córdoba no atribuye a la ciudad nombrada un conjunto de notas. No hay un modo determinado de ser Córdoba. Luis nombra y diferencia a un individuo, pero no se refiere a ciertas cualidades en que consiste ser Luis. No hay un modo determinado de ser Luis $^{31}$.
\end{abstract}

Según podemos leer en su exposición, el nombre común, al designar a su objeto, lo connota. EI nombre propio lo denota simplemente, sin connotación.

En gramáticas castellanas posteriores, encontramos frecuentes explicaciones del nombre propio que repiten en términos parecidos la que aparece en la cita anterior: por una parte se les incluye en la clase de los sustantivos; $y$, por otra

3 A. Alonso y P. Henríquez Ureña, Gramática castellana. Segundo curso, Buenos Aires, Losada, 1971, págs. 37-38. 
parte, se señalan las diferencias de función semántica entre ambos, diferencias que, en nuestra opinión, no permitirían tal agrupación.

S. Gili Gaya ${ }^{32}$, de manera vacilante, expone que «únicamente los nombres propios, representativos de seres individuales, carecen al parecer de valor conceptual». Caracterizamos su clasificación de los nombres propios como «vacilante» no sólo por la utilización de «al parecer» en la aseveración anterior, sino porque su definición de los sustantivos como clase está más próxima a los puntos de vista que hemos considerado de carácter intensional, pues, para él,

los substantivos se piensan en sí mismos, como representaciones o conceptos independientes. Pueden designar personas (Juan), cosas (árbol), cualidades físicas o morales (empujón), estados (quietud), es decir, cualquier fragmento de la realidad o aspecto de la realidad considerado como objeto independiente de nuestro pensar.

Mucho más próxima a la interpretación de A. Alonso y P. Henríquez Ureña es la que podemos ver en Alcina y Blecua:

Frente a la fuerza connotativa de la mayor parte de los nombres de la lengua, el nombre propio particulariza un determinado y concreto referente sin connotarlo. Tiene función denominativa. Mientras nombres como perro, mujer, diosa y yegua por sí mismos informan al hablante de unas determinadas cualidades y atributos que se dan en los sujetos que se ha convenido en llamar así, el nombre Diana -que se puede emplear para particularizar a una diosa, una mujer, una perra o una yegua - no connota de antemano por sí mismo ninguna cualidad particular.

Los nombres propios son, pues, por sí mismos, nombres sin significación propia ${ }^{33}$.

Naturalmente, no podemos aceptar que se diga de un signo o de un tipo de signos que no tiene significación propia, pues o bien no serían signos, o bien tendríamos que revisar nuestra definición de significación, o significado. Algo semejante, e igualmente inaceptable, entendemos que se expresa en F. Marcos, F. J. Satorre y M. ${ }^{2}$ L. Viejo ${ }^{34}$, cuando afirman que los sustantivos propios «son sustantivos en los que el significante se une directamente al referido sin que intervenga el significado». Y la distinción que establecen entre el nombre propio y el nombre común como ausencia de connotación en los nombres propios es también semejante, pues afirman que «con el nombre propio se identifica la realidad nombrada, pero no se aporta ninguna nota significativa relativa a dicha realidad».

${ }^{32}$ S. Gili Gaya, Curso superior de sintaxis española, Barcelona, Vox, 1964, pág. 100.

${ }^{33}$ J. Alcina y J. M. Blecua, Gramática española, Barcelona, Ariel, 1994, págs. 501-502.

${ }^{34}$ F. Marcos, F. J. Satorre y M." L. Viejo, Gramática española, Madrid, Síntesis, 1998, pág. 119. 
A. di Tullio también incluye entre los sustantivos la subclase de los sustantivos propios, que se caracterizan por ser expresiones referenciales por sí mismas:

Los sustantivos propios denotan individuos por medio de una asociación directa con su referente. Idealmente, cada nombre identifica un individuo de manera no ambigua. Carecen de significado ya que consisten sólo en etiquetas que se asignan a los individuos para su identificación ${ }^{35}$.

Finalmente recogemos en este apartado una de las últimas reflexiones acerca de los nombres propios aparecidas en los estudios gramaticales sobre el español. En ella se reflejan de manera clara las limitaciones de esta explicación. Nos referimos al estudio de M. Jesús Fernández Leborans. En él se afirma que los nombres propios constituyen una clase de palabras subordinada a la categoría del nombre. El rasgo específico de los nombres propios es que

\begin{abstract}
se trata de expresiones propiamente, pero no exclusivamente, referenciales, a diferencia de los NNCC, que son expresiones propiamente predicativas. Los NNPP son signos dotados de referencia, y derivativamente, de significado, lo que equivale a decir que su función referencial no es inducida lingưísticamente por su significado [...].

Digamos que el nombre propio no tiene un significado léxico, en acepción linguística convencional; un NP no se opone a otros NNPP por sus propiedades o rasgos semánticos, dado que estos no pueden constituirse en una descripción más o menos precisa, única y estable del referente, mientras que los rasgos del nombre común pueden ser definidos mediante descripciones de este tipo ${ }^{36}$.
\end{abstract}

En esta última interpretación vemos reflejado en buena medida el carácter problemático de la inclusión de los nombres propios en la categoría de los sustantivos. En los casos anteriores, en nuestra opinión, se daba una caracterización adecuada de los nombres propios, pues se ponía de relieve su función designativa carente de connotación (aunque no podemos aceptar que carezcan de significado); pero no eran caracterizados adecuadamente los sustantivos, pues se les atribuía función designativa, aunque con presencia de connotación, lo cual podría justificar su inclusión en la clase de los nombres. En la exposición de $M^{2}{ }^{2}$ Jesús Fernández, se caracteriza, de manera razonable en nuestra opinión, a los nombres comunes como expresiones propiamente predicativas, no designativas. Esto, coherentemente, obligaría a excluir los nombres propios de la categoría de los sustantivos. Sin embargo, para justificar su inclusión en la misma categoría, afirma que la explicación expuesta «no implica de manera al-

${ }^{35}$ A. di Tullio, Manual de gramática española, Buenos Aires, Edicial, 1997, pág. 148.

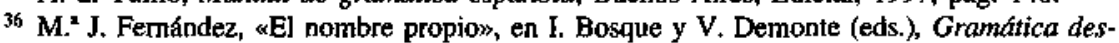
criptiva de la lengua española I, Madrid, Espasa, 1999, págs. 77-128, pág. 102. 
guna, el vacío de significado; no se trata, como se ha observado anteriormente, de expresiones deícticas, sino de signos que contienen - de un modo no decidido aún- el 'concepto' de individuo al que se refieren — su referente inicial— ${ }^{37}$.

Estamos comprobando las dificultades de la teoría del significado como concepto para la clasificación de los signos lingǘsticos. En todos los casos vistos en este último apartado, observamos cierta dificultad para incluir los nombres propios en la clase de los sustantivos, pues, o bien tenemos que atribuir una función designativa a los sustantivos, cosa que por sí mismos parece que no tienen, o bien tenemos que atribuir algún tipo de intensión a los nombres propios. Sin alguna de estas concesiones no estaría justificada la inclusión de los sustantivos y de los nombres propios en la misma categoría. Ambas cuestiones están presentes a lo largo de este trabajo.

Junto a las diferentes propuestas clasificadoras vistas, tenemos también testimonios que señalan la dificultad para diferenciar los nombres propios de los sustantivos, con lo cual se está proponiendo la existencia de una sola clase de nombres. Tanto las propuestas que defienden la existencia de los nombres propios como una subclase dentro los nombres, como las que niegan la existencia de tales subclases se basan, como no podría ser de otra forma, en la caracterización dada de los nombres propios.

Así, $\mathrm{O}$. Jespersen ${ }^{38}$, que atribuye a los nombres propios un contenido intensional semejante al de los nombres comunes, afirma que, «linguísticamente, es imposible trazar una línea de separación entre los nombres propios y los nombres comunes», por lo que concluye «que no existe una frontera clara entre los nombres propios y los nombres comunes, pues la diferencia es más cuantitativa que cualitativas.

La RAE ofrece observaciones acerca de los nombres propios y de los nombres comunes; pero, en nota a pie de página, de manera sintomática en nuestra opinión, afirma que «es difícil fundamentar esta distinción con criterios gramaticales, probablemente porque nada tiene que ver con la gramática» ${ }^{39}$.

$\mathrm{Y}$, fimalmente, recogemos la opinión de Gilles Granger ${ }^{40}$, que, basándose en la obra de Lévi-Strauss El pensamiento salvaje, atribuye a los nombres propios una función esencialmente clasificadora y relacional. El único rasgo caracterizador del nombre propio es que puede ser usado en la interpelación, pero, dado que todo signo puede funcionar como nombre propio, la especifici-

37 Ibid., pág. 102.

38 O. Jespersen, La filosofia de la gramática, Barcelona, Anagrama, 1975, págs. 68-69.

39 RAE, Esbozo de una nueva gramática de la lengua española, Madrid, Espasa, 1991, pág. 172 .

40 G. Granger, «A quoi servent les noms propres?», en Langages 66, 1982, págs. 21-36, pág. 29. 
dad del nombre propio es sólo de naturaleza pragmática. Por lo tanto, para Granger, el nombre propio no se diferencia del sustantivo ni se puede asimilar a ningún de deíctico.

La clasificación binaria de los signos en lexemas y morfemas, que seguimos en este estudio, tiene sus dificultades. Prueba de ello es la propuesta de E. Coseriu para clasificar las palabras en lexemáticas, morfemáticas y categoremáticas, con lo cual, aunque se hable de palabras, se está proponiendo una clasificación tripartita de los signos. También podemos considerar que es una prueba de esta dificultad la clasificación seguida por $\mathrm{L}$. Tesnière en palabras llenas y palabras vacías, pues inmediatamente después tiene que introducir una nueva subclasificación dentro de las llenas, con lo que se llega de hecho a la clasificación tripartita propuesta por E. Coseriu. Venimos repitiendo que la clasificación va a depender de la caracterización que expongamos de los signos y, en el punto de partida, de la definición que demos de significado. Por todo esto, no es sorprendente que, en los estudios sobre los nombres propios, encontremos propuestas clasificadoras en las que el nombre propio es considerado como una categoría primaria de signos no incluida en ninguna otra categoría.

Esta pluralidad de enfoques y de interpretaciones no es algo exclusivo del nombre propio. Podríarnos afirmar que cualquier clase de signos, de construcciones o de relaciones sintácticas que tratemos han sido interpretados de todas las maneras posibles. En el caso del nombre propio, como hemos podido comprobar, todas las interpretaciones posibles consisten en su asimilación como una subclase dentro de otras categońas (sustantivos o deícticos) o en su consideración como una categoría no incluida en otras categonias. No todas las explicaciones o caracterizaciones pueden ser igualmente adecuadas o pueden ser complementarias unas de otras, aunque sí es cierto que, en nuestra opinión, una comprensión adecuada del funcionamiento de los signos puede permitimos entender por qué se han dado las diferentes explicaciones que se han dado.

J. Algeo rechaza su consideración como elementos vacíos de significado, así como su consideración como deícticos; y propone su inclusión en el lexicón. Hay que señalar que la palabra lexicón tal como la utiliza J. Algeo, de acuerdo con una parte importante de la linguística actual, no es un término técnico para una clase de signos, sino más bien un término técnico para un componente de la gramática, aquel en el que se recoge el inventario de todos los signos de la lengua. Por ello, en nuestra opinión, no debemos entender que se esté incluyendo a los nombres propios entre los lexemas, en el sentido que usamos la palabra para referirnos a una clase de signos. J. Algeo expone su propuesta clasificadora en los términos siguientes:

It may be said that there are three main kinds of vocables in the lexicon: those words that form closed systems in the grammar, such as articles, pro- 
nouns, auxiliaries, and some prepositions and conjunctions, second, apellative nouns and those verbs, adjectives and forth that form open sets and constitue the bulbk of words listed in general dictionaries; and last, names, which are often excluded from dictionaries on either theoretical or practical grounds ${ }^{41}$.

Pero, aunque desde un punto de vista teórico no encuentra razones para excluir los nombres propios del lexicón, reconoce que, dado su elevado número y la cantidad de información linguística apropiada para cada uno de ellos, hay razones prácticas para dejarlos fuera del diccionario.

La propuesta de Jean Molino responde a un punto de vista distinto, pero coincide en considerar los nombres propios como una clase diferente de signos no incluida en otras clases. Se pregunta cuál es el lugar de los nombres propios en la lengua y propone la siguiente clasificación de los signos:

champ du nom propre.

champ déictique

champ de la répresentation

Nous reprenons ici la distinction proposée par Bühler, pour lequel il existe dans la langue un champ de la deixis (composé de tous les éléments qui renvoient aux trois dimensions de la deixis: moi, ici et maintenant) et un chanp de la répresentation (auquel appartiennent les autres éléments du langage, noms et verbes). II nous semble que le nom prope constitue un autre champ linguistique, qui occupe une place intermédiaire entre les deux autres ${ }^{42}$.

Esta propuesta clasificadora se justifica porque, para Jean Molino, los nombres propios son nombres; pero, por su funcionamiento, están más próximos a los deícticos, en concreto a los pronombres personales. Y es esta situación intermedia la que permite explicar sus propiedades lingüísticas: se trata de la utilización del campo de la representación según el modelo del campo deíctico. Como vemos, aquí encontramos resumidas todas las posibilidades teóricas para una clasificación de los nombres propios: entre los sustantivos, entre los pronombres o como una clase diferente.

Extraña, y también diferente, es la caracterización y clasificación de A. López, para quien «el nombre propio vale por una palabra que se comporta como una oración» ${ }^{43}$; pero precisa que esta definición como palabra que se articula oracionalmente alude a sus características como clase y no a ocurrencias particulares, es una caracterización paradigmática, no sintagmática. Años después vuelve a tratar el tema de los nombres propios ${ }^{44}$. Pero tenemos que reconocer

41 J. Algeo, On defining the proper name, Florida, Ganesville, 1973, pag. 75,

42 J. Molino, «Le nom propre...», pág. 19

43 A. López, «Lo propio del nombre propion, en $L E A$ VП, 1985, págs. 37-54, pág. 41.

44 A. López, Gramática del español III. Las partes de la oración. Madrid, Arco/Libros, 1998, pág. 107. 
que, en ambos textos, no vemos demasiado claro los motivos que le llevan a clasificar y caracterizar el nombre propio como palabra que se comporta como una oración: si por oración entendemos un tipo de construcción sintáctica, como sujeto + predicado, no parece que el nombre propio sea equivalente; si por oración entendemos una unidad de comunicación, un enunciado, cualquier signo o construcción con referencia autónoma puede serlo.

En cualquier caso, estamos ante un ejemplo más de las propuestas clasificadoras que consideran el nombre propio como una categoría independiente, con características no compartidas por otras clases de signos.

Lieven Vandelanotte y Peter Willmense, desde los planteamientos de la lingüística cognitiva, no pretenden establecer una clasificación de los signos; pero abogan por la consideración de los nombres propios como una clase diferente de entradas en el diccionario, a la que llaman propial lemmas, «which has as prototypical function the realization of the grammatical category of proper names» ${ }^{45}$. Pero los términos lexicon y diccionario están utilizados como términos técnicos para uno de los componentes de la gramática, y no como una denominación para una clase de signos, según hemos expuesto. Frente a los propial lemmas los nombres propios son una clase sintáctico-semántica que tiene unos rasgos prototípicos, como son la singularidad, la definitud, la no genericidad y la concreción. Estamos ante una clase de signos no incluida en ninguna otra y con rasgos propios, pero esta clase estaría constituida por los propial lemmas, pues, en su función de nombres propios, comparten ese papel con otras clases de signos y construcciones.

\section{LA FUNCIÓN SEMÁNTICA DE LOS NOMBRES PROPIOS}

Según hemos podido comprobar, y lógicamente no puede procederse de otra forma, las propuestas clasificadoras de los nombres propios vistas se fundamentan en la descripción de las características atribuidas a este tipo de signos. Pero no siempre que se procede a una caracterización de los nombres propios se llega a una clasificación de los mismos o se los incluye entre otras clases de signos. Quizás, en nuestra opinión, uno de los casos más sintomáticos de lo que estamos afirmando sea el estudio ya clásico sobre los nombres propios de Sir Alan Gardiner. En este trabajo, a pesar del rigor y finura del análisis con que se estudian los nombres propios, no se contempla su inclusión en otras clases de signos. No obstante, la definición o caracterización del nombre propio que Gardiner nos ofrece es una de las más minuciosas que hemos encontrado:

\footnotetext{
${ }^{45} \mathbf{L}$. Vandelanotte y P. Willmense, «Restrictive and non restrictive modification of propial lemmas», en Word, 53.1 2002, págs. 9-36, pág. 11.
} 
A proper name is a word or group of words which is recognized as having identification as its specific purpose, and which achieves, or tends to achieve, that purpose by means of distinctive sound alone, without regard to any meaning expressed by that sound from the start acquired by it through association with the object or objects thereby identified ${ }^{46}$.

Por este motivo, metodológicamente, hemos separado en nuestra exposición la clasificación de los nombres propios de las diferentes explicaciones que se han dado de su significado, aunque teóricamente no es posible clasificar sin caracterizar. Queremos insistir también en que, en nuestra opinión, las caracterizaciones del nombre propio, como las de cualquier otra clase de signos, deben consistir en una explicación de su función semántica, pues, por principio, cualquier cosa que sea considerada signo en una lengua es significante, en el sentido etimológico del término.

La caracterización de la función semántica de los nombres propios no es tarea fácil: con razón J. Algeơ afirma que después de veinticuatro siglos de estudios sobre el nombre propio es destacable el hecho de que en la actualidad apenas hay acuerdo acerca de qué es un nombre propio. Para tratar de evitar algunas confusiones, propone limitar su objeto de estudio a aquellas «linguistic forms that can be called proper names in ordinary language» ${ }^{47}$.

Esta misma dificultad ha llevado a algunos estudiosos a rechazar la posibilidad de definir los nombres propios, y ofrecen una visión de los mismos que podemos considerar ecléctica o, incluso, escéptica. J. Molino ${ }^{48}$ se pregunta si se pueden definir los nombres propios; y él mismo responde: «nous ne le croyons pas», pues, en su opinión, ningún criterio permite por sí mismo separar sin ambigiedad los nombres propios de los nombres comunes; y, por otra parte, los criterios utilizados no son convergentes, es decir, los diferentes criterios utilizados no delimitan el mismo dominio. Esta hipótesis es válida para cualquier categoría de signos: «il n'existe pas des catégories linguistiques bien définies», lo cual es coherente con los principios de la linguística cognitiva de los que parte.

No obstante, a pesar de las dificultades y a pesar del escepticismo, ante la pregunta sobre cuál es el significado del nombre propio ha habido fundamentalmente dos tipos de respuestas: los nombres propios carecen de significado (intensión o sentido), respuesta representada por S. Mill; los nombres propios tienen significado (sentido o intensión), respuesta representada, entre otros, por G. Frege, B. Russell, O. Jespersen, etc. En cada una de estas caracterizaciones

${ }^{46}$ Sir A. Gardiner, The Theory of Proper Names, London, Oxford University Press, 1954, pág. 73.

47 J. Algeo, On defining..., pág. 9.

${ }^{48} \mathrm{~J}$. Molino, «Le nom propre...», pág. 8. 
del nombre propio, podremos comprobar posturas diferenciadas, pues, como escribió J. Searle ${ }^{49}$, ambas posiciones tienen argumentos a su favor y ambas tienen dificultades; de ahí los sucesivos intentos para definir de una manera más precisa cuál es el valor de los nombres propios o cuál es la forma en que desempeñan la función designativa.

En algunos estudios recientes se habla de que hay entre los linguiistas tres posiciones respecto al valor de los nombres propios. Así lo podemos ver en Mary-Noëlle Gary-Prieur. Las dos primeras posiciones coinciden con las expuestas: los nombres propios no tienen sentido, los nombres propios tienen un sentido del mismo tipo que los nombres comunes. La tercera teoría se ha desarrollado, en su opinión, en los últimos veinte años, y consiste en que

on peut donc proposer d'attribuer au nom propre un 'sens instructionnel' du même type que celui d'un determinant. Ce sens consiste à donner l'instruction d'associer à la forme du nom propre un individu dont on sait, dans une situation d'énontiation donnée, qu'il est l'unique porteur du nom à prendre en considération ${ }^{50}$.

Esta relación es la que constituye, para ella, el sentido del nombre propio.

Los términos utilizados frecuentemente nos pueden llevar a confusión. En nuestra opinión, en castellano es preferible hablar de significado, en vez de sentido, si nos referimos a tipos de signos. El término sentido sería más apto para hablar de la información que transmite un signo en un uso particular.

En un nivel estrictamente teórico, las posiciones acerca del significado de los nombres propios sólo podrían ser tres, lo mismo que para cualquier otra categoría de signos: el significado es una realidad mental o intensional, el significado es de carácter extensional y se identifica con la realidad referida; y, por último, el significado es la función o el uso que hacemos de los signos.

A continuación nos referimos brevemente a las diferentes teorías y exponemos una valoración de las mismas.

\subsection{La teoría referencial}

Según esta teoría, los nombres propios no connotan. Para S. Ullmann ${ }^{51}$, esta teoría tiene su locus classicus en el libro I, Cap. 2 de A System of Logic

\footnotetext{
49 J. Searle, «Nombres propios y descripciones», en L. MI. Valdés Villanueva (ed.) La búsqueda del significado, Madrid, Tecnos, 1991, págs. 83-93, pág. 85.

so Mary-Noèlle Gary-Prieur, L'individu pluriel: les noms propres et le nombre, Paris, Centre National de Ja Recherche Scientifique, 2001, págs. 9-10.

51 S. Ullmann, Semántica. Introducción a la ciencia del significado, Madrid, Aguilar, 1972, pág. 83.
} 
de John Stuart Mill. En nuestra opinión, tiene su mayor dificultad en una concepción metonímica del significado que, en línea con la definición saussureana, viene a identificar el significado con el concepto, la intensión o connotación -n definitiva, según hemos expuesto, el significado se identifica con un objeto mental. Esta dificultad lleva a algunos lingüistas, como el propio S. UI1mann, a afirmar que «los nombres propios no tienen significado y, por consiguiente, no se aplica la noción de significación. La función de un nombre propio es la identificación pura: distinguir o individualizar a una persona o una cosa con ayuda de un marbete especial» ${ }^{52}$. Y en la obra anterior insiste en que «la función del nombre propio es identificar y no significar ${ }^{53}$, como si identificar — decimos nosotros- no fuera la forma de significar de los nombres propios.

Esta función identificadora del nombre propio ha sido expuesta en diferentes tiempos y en diferentes lenguas. Bruno Migliorini hace suya la definición de H. Bertelsen, según la cual «un nome appellativo domina il suo oggetto alludendo a condizioni che sono propie all'individuo o agl'individui a cui si riferisce; un nome proprio denomina il suo oggetto senza alludere a condizioni propie all' individuo o agl'individui a cui si riferisce» ${ }^{54}$.

La afirmación frecuente de que los nombres propios no tienen significado puede venir motivada también por su constante asociación con los sustantivos, pues de ella, efectivamente, parece desprenderse que estos expresan algunas características del objeto, cosa que no manifiestan los nombres propios. Esta misma asociación puede haber inducido también a postular un significado descriptivo para los nombres propios, en un intento de poder asimilarlos a los sustantivos.

$\mathrm{La}$ atribución de una función designativa a los nombres propios no puede llevarnos a la consideración de que el significado del nombre propio es el objeto designado. Esto lo expuso de manera clara L. Wittgenstein: «La oración 'Nothung tiene un tajo afilado' tiene sentido también cuando Nothung ya está destrozada. Ahora bien, esto es así porque en este juego de lenguaje se usa también un nombre en ausencia de su portadons ${ }^{55}$. Franz von Kutschera recoge el punto de vista de Wittgenstein y señala que un nombre propio no pierde su significado por el hecho de que el objeto que designa deje de existir: «Debemos, pues, distinguir el significado de un nombre propio de su referencia, es decir, del objeto que designa» ${ }^{56}$.

52 S. Ullmann, Introducción a la semántica francesa, Madrid, RFE, 1965, pág. 31.

${ }^{53}$ S. Ullmann, Semántica..., pág. 82.

${ }^{54}$ Br. Mogliorini, Dal nome propio al nome comune, Firenze, Leo S. Olschki Editore, 1968, pág. 5.

${ }^{55}$ L. Wittgenstein, Investigaciones filosóficas, Barcelona, Ed. Crítica, 1988, pág. 61.

${ }^{56}$ Fr. Von Kutschera, Filosofia del lenguaje, Madrid, Gredos, 1979, pág. 48. 
No obstante, en algunos estudios, creemos que se ha producido esa identificación entre significado y referente. Thomas S. Sebeok afirma que

se llama nombre a un signo que tiene una clase extensional para su designado. Según esta definición, los individuos denotados por un nombre propio, como por ejemplo Verónica, no tienen atribuida una propiedad común excepto el hecho de que todas ellas responden a «Verónica». Una definición extensional de clase es la que viene dada por «la enumeración de los nombres de sus miembros sucesivamente» ${ }^{57}$.

Entendemos que una definición extensional sólo tiene sentido en lógica, como una de las posibles opciones dentro de la teoría de conjuntos, la que procede mediante la enumeración de los miembros del conjunto; pero una definición linguística de una clase de signos siempre debe proceder señalando sus características; y pertenecerán a la categoría todos los signos que tengan las características atribuidas a la clase.

Por este motivo, entendemos que la caracterización de la función designativa de los nombres propios que propone P. F. Strawson es adecuada:

Se dice a veces que los nombres propios ordinarios son esencialmente palabras, cada una de las cuales se usa para referirse a un individuo. Esto es evidentemente falso. Muchos nombres personales ordinarios - los nombres par excellence - se usan correctamente para referirse a muchas personas. Un nombre personal ordinario es, a grandes rasgos, una palabra usada referencialmente, cuyo uso no está dictado por ningún significado descriptivo que pueda tener la palabra, $n i$ está prescrito por ninguna regla general para su uso como expresión referencial (o como parte de una expresión referencial) tal como encontramos en el caso de palabras como «yo», «esto» y «él», sino que está gobemado por convenciones ad hoc, para cada conjunto particular de aplicaciones de la palabra a una persona dada ${ }^{58}$.

Quizás podríamos matizar que «las convenciones ad hoc para cada conjunto de aplicaciones de la palabra a una persona dada» forman parte de una convención general, pues el uso de los nombres propios se convierte en categoría de signos en la medida en manifiestan unas regularidades generales. $Y$ son estas regularidades las que los constituyen en uno de los usos o juegos del lenguaje. Otra cosa diferente es que las formas esto o yo tengan un campo de aplicación más general que el que corresponde a los nombres propios.

En cualquier caso, como afirma P. F. Strawson, usamos los nombres propios con función designativa, para referimos a un objeto. Leonard Linsky escribió que es de la mayor importancia la consideración de que

${ }^{57}$ Th. S. Sebeok, Signos: una introducción a la semiótica, Barcelona, Paidós, 1996, pág. 52.

s8 P. F. Strawson, «Sobre el referir», pág. 78. 
it is the users of language who refer and make references and not, except in a derivative sense, the expressions which they use in so doing. [...] What is indeed necessary, if I am make a definite assertion is not that one person only be named Tomy Jones; but that $I$ be referring to just one person ${ }^{59}$.

Ha habido algunos intentos de precisar el significado de los nombres propios que, en nuestra opinión, se pueden incluir en la que hemos denominado teoría referencial, pues, en realidad, tratan de explicar de qué modo desempenan los nombres propios la función designativa. Entre ellos destacamos la propuesta de J. Searle y de S. Kripke.

J. Searle, partiendo de la teoría de B. Russell, se pregunta si tienen sentido los nombres propios; y analiza las dos respuestas dadas a esta pregunta: los nombres propios denotan, pero no connotan; los nombres propios son descripciones abreviadas. Encuentra dificultades para aceptar la validez de cualquiera de ellas. Por este motivo concluye así:

mi respuesta a la pregunta « ¿Tienen sentido los nombres propios?» -Si esta pregunta plantea si los nombres propios se usan para describir o especificar características de los objetos- es «No». Pero si plantea si los nombres propios están o no conectados lógicamente con características del objeto al que hacen referencia, la respuesta es «Sí, de una manera laxa» ${ }^{60}$.

J. Searle presenta su propuesta como una especie de compromiso entre Frege y Mill, pues, por una parte, es cierto que los nombres propios no entrañan ninguna descripción particular, no se pueden definir; pero también es cierto que cualquier término particular debe tener algún modo de presentación $\mathrm{y}$, por lo tanto, de alguna manera, un sentido.

Este modo de presentación es para Searle una descripción identificadora, lo cual quiere decir que tanto el hablante como el oyente son capaces de asociar alguna descripción identificadora al nombre propio, aunque esta descripción identificadora difiera entre ellos.

La explicación de J. Searle de los nombres propios, en nuestra opinión, se debe incluir en la teoría referencial. Su reflexión incide sobre todo en los aspectos pragmáticos de la referencia, en la medida en que explica qué condiciones deben darse para que el acto de referir mediante un nombre propio sea adecuado o afortunado. Se trata, en definitiva, de que el hablante y el oyente deben entender el sentido en el que se usa el nombre propio, es decir, el objeto al que se refieren, para que la comunicación funcione; de la misma manera que deben entender aquello a lo que se refiere cualquier otro signo o construcción.

${ }^{59}$ L. Linsky, «Reference and referents», en D. D. Steinberg y A. Jakobovits (eds.) Semantics, Cambridge, University Press, 1975, págs. 76-85, pág. 76-77.

60 J. Searle, Actos de habla, Madrid, Cátedra, 1986, pág. 173. 
Ciertamente la identificación del referente puede llevarse a cabo aludiendo a algunas características del objeto; pero también puede realizarse mediante otros procedimientos, que también sirven para identificar el objeto. Si hablamos de Juan y nos preguntan de quién estamos hablando, podemos identificar el referente mediante alguna aclaración identificadora del tipo «el hijo de mi vecina»; pero también lo podemos hacer mediante construcciones del tipo «de Juan Ruiz Pérez».

S. Kripke ${ }^{61}$ desarrolla su reflexión sobre los nombres propios, como no podía ser de otra manera, a partir de las teorías opuestas de Mill y Russell, o Frege. Para él, el problema fundamental de la teoría de Mill es saber cómo se puede determinar el referente de un nombre. Parte de manera intuitiva de la tesis de que «les noms sont désignateurs rigides». Su explicación de los nombres propios puede ser incluida entre el conjunto de explicaciones que hemos llamado teoría referencial, y, como en el caso de J. Searle, trata de precisar la forma en que los nombres propios desempeñan esa función referencial designativa.

Rechaza, naturalmente, que la referencia del nombre propio se establezca mediante algún rasgo descriptivo o mediante un conjunto de rasgos descriptivos del objeto, pues podría ocurrir que, en otros mundos posibles, esos rasgos no se dieran en el objeto. Por lo tanto la descripción sólo debe servir para fijar la referencia; así el referente de Aristóteles será siempre el mismo, en cualquier mundo posible, independientemente de las características que atribuyamos al referente.

Aquello a lo que hacemos referencia depende del grupo social y de la historia del nombre. Hay, en opinión de Kripke, lo que él llama bautismo social. En el momento del bautismo social se puede fijar la referencia ostensivamente o mediante una descripción; y a partir de ese momento los usuarios del nombre propio deben hacerlo con la intención de hacer la misma referencia que hizo la persona de la que aprendieron el nombre.

El planteamiento de Kripke, aunque utiliza otro tipo de argumentación y de terminología, es muy semejante al de J. Searle, pues los designadores rígidos implican la identidad del referente, que era la cuestión que J. Searle pretendía salvar mediante lo que él llamaba la presentación del objeto o la descripción identificadora. La aportación de J. Kripke va destinada a explicar cómo se produce la función designativa del nombre propio; y habría que situarla en el campo de la pragmática. Esta interpretación que proponemos de la teoría de Kripke coincide con la valoración que de la misma realizó François Recanati, que considera la teoría de Kripke como una vuelta a Mill:

${ }^{61}$ S. Kripke, La logique des noms propres, Paris, Les Éditions de Minuit, 1982. 
Dire que la relation de désignation qui associe le nom propre à l'objet est rigide c'est dire qu'elle n'est pas affectée par le changemente du monde de référence, et dire cela c'est dire qu'elle n'est pas fonction des propriétés de l'objet, dans la mesure où ce sont ces propriétés qui varient du monde à monde. De là résulte que contrairement aux descriptions définies les noms propres sont attachés aux objets mêmes et ne dependent pas de la permanence de tel ou tel attribut ${ }^{62}$.

$\mathrm{Y}$, aunque es cierto que algunas descripciones definidas pueden ser consideradas también designadores rígidos, los nombres propios son intrínsecamente designadores rígidos.

La teoría de los designadores rígidos es, en nuestra opinión, la explicación más completa y adecuada del significado de los nombres propios dentro de la teoría referencial. Ha sido denominada teoría causal de los nombres propios; y numerosos lingüistas se han hecho eco de ella. Robert M. Martin, dentro de su teoría extensional del significado, escribe:

Once a proper name is stablished, one need not use it with any sort of direct connection with the individual named: we can use the proper names of people who are far away or even dead [...]

A causal chain thus makes if the case no that uses of the name are connected to the individual named [...].Thus this view is sometimes known as the causal theory of proper names ${ }^{63}$.

Dentro de la teoría referencial del nombre propio, podemos incluir también los diferentes estudios que lo definen como un predicado de denominación. La propuesta más difundida pertenece a G. Kleiber ${ }^{64}$. De él la toma Mary-Noëlle Gary-Prieur para su estudio sobre la gramática de los nombres propios: «Dans toute la suite de ce travail, $\mathrm{j}$ 'entendrai par sens une proprieté que caractérise le nom propre en tant que unité de la langue, et qui est à mon avis très bien représentée par la predicat de dénomination» ${ }^{65}$.

La definición de un nombre propio como predicado de denominación no implica que ese sea el sentido del nombre propio; en castellano, según hemos expuesto, deberíamos emplear el término significado y hablar de sentido sólo para la información pragmática que es transmitịa por los usos particulares de los signos o las construcciones en las situaciones comunicativas en que se utilizan.

${ }^{62}$ Fr. Récanati, «La sémantique des noms propres», en $\operatorname{LFr} 57,1983$, págs. 106-118, pág. 110.

${ }^{63}$ R. M. Martin, The Meaning..., pág. 173.

${ }^{64} \mathrm{G}$. Kleiber, Problèmes de référence: descriptions definies et nom propre, Paris, Klincksieck, 1981.

${ }_{65}$ Mary-Noêlle Gary-Prieur, Grammaire.., pâg. 39. 
Pero la definición del nombre propio como predicado de denominación, si no lo hemos entendido mal, está ya en el estudio de J. Algeo. Alli leemos que «a proper name may be defined as a word whose definition includes a citation of word itself» ${ }^{66}$, $\mathrm{y}$ «More generally, a proper name is primarily any word $\mathrm{X}$ whose meaning can be expressed as 'entity called $X$ ' and secondarily any whose inmediate definientia include a term with such meaning» 67 .

Nuestra opción por incluirla entre las teorías referenciales está justificada en cierta medida por el mismo J. Algeo, que considera que su definición está implícita en la obra de Mill: la observación de Mill de que «when we predicate of anything its proper name, when we say, pointing to a man, this is Brown or Smith, or pointing to a city, that is York, we do not, merely by so doing, convey to the hearer any information about them, except that those are their names» ${ }^{68}$.

Esta definición de los nombres propios como predicados de denominación ha sido considerada por algunos como una definición estrictamente linguíistica, frente a las definiciones referenciales que emanan de los lógicos; pero, en nuestra opinión, es más bien una definición metalingüística, en el sentido de que define de forma más precisa el uso metalingüístico de los nombre propios --en frases del tipo Este se llama Juan-que el uso lingüistico o referencial -en frases del tipo Juan viene mañana, No he visto a Juan. Quizás por ello el mismo Algeo admite que su definición puede dar la impresión de circularidad, si definimos el significado de Thomas como la persona así llamada.

Esta desviación de este tipo de definiciones ha sido expuesta por $\mathbf{M}^{2}$. Jesús Fernández, de las que afirma lo siguiente:

No obstante, este tipo de definiciones metalingüísticas poseen carácter claramente derivativo - las descripciones de este tipo 'el individuo llamado NP' $o$ 'el individuo que es un portador de NP' no son primitivas; derivan del uso previo de NP para designar a su portador, con la particularidad de que se basan en la condición pragmática de la referencia ${ }^{69}$.

En resumen, no creemos que la definición de los nombre propios como predicados de denominación sea una forma adecuada de explicar su significado. Cuando decimos Juan viene mañana estamos designando un referente particular y concreto, suponemos que, si seguimos las convenciones ad hoc, el individuo designado se llama Juan; pero esto es algo que no aseveramos. Ś́lo en los casos en que usamos el término Juan de forma metalingüística, Mi ami-

\footnotetext{
${ }^{66}$ J. Algeo, On defining.... pág. 69

${ }^{67}$ Ibid., pág. 70.

68 lbid., pág. 83.

${ }^{69}$ M. J. Fernández Leborans, «E] nombre propio», pág. 99.
} 
go se llama Juan, el signo Juan es realmente un predicado de denominación; pero en estos casos el signo no tiene función designativa, que es el uso lingüístico de los nombres propios.

\subsection{La teoría conceptual o intensional}

El conjunto de interpretaciones o definiciones de los nombres propios que incluimos bajo la denominación de teoría conceptual es conocido normalmente como teoría descriptiva de los nombres propios, pues tiene como uno de sus impulsores a B. Russell, que asimiló los nombres propios a las descripciones definidas. Pero en lingüística no tenemos una teoría «descriptiva» del significado, sino una teoría conceptual, en la cual habría que incluir esta definición de los nombres propios. La teoría ha sido explicada en muchas ocasiones; y por ello la vamos a tratar de manera breve. Entre sus proponentes, además de B. Russell, hay nombres tan conocidos como G. Frege, M. Bréal, O. Jespersen y, más recientemente, U. Eco. Y, lo mismo que hemos visto en Ja teoría referencial, no todas las caracterizaciones que incluimos en este apartado son coincidentes. Hay diferencias no sólo en el tipo de significado descriptivo o conceptual que se le atribuye al nombre propio, sino también en el mayor o menor énfasis que se pone en la función referencial o designativa, pues, postular un contenido intensional para los nombres propios no supone necesariamente pasar por alto su función designativa.

G. Frege, como es normal en lógica, llama nombre propio a todo signo o construcción que nombra un objeto, algo parecido a lo que en la lingǘstica actual que aplica la lógica de predicados se llama término. Y distingue el referente del sentido. Afirma que

en el caso de un verdadero nombre propio como 'Aristóteles', naturalmente pueden dividirse las opiniones en cuanto a su sentido. Por ejemplo, se podría suponer que este sentido es: el discípulo de Platón y maestro de Alejandro Magno. Quien suponga esto atribuirá al enunciado «Aristóteles era originario de Estagira» un sentido distinto de aquel para quien el sentido de este nombre fuera: el maestro de alejando Magno originario de Estagira. Mientras la referencia siga siendo la misma pueden tolerarse estas vacilaciones de sentido ${ }^{70}$.

En realidad, lo que Frege llama sentido es el conocimiento indispensable que hablante y oyente deben tener para identificar el referente; pero lo único indispensable, como él mismo escribe, es que la referencia sea la misma. Esto nos recuerda el trabajo de L. Vygotsky ${ }^{71}$ en el que expone que el niño y el

${ }^{70}$ G. Frege, Estudios sobre semántica, Barcelona, Ariel, 1984, págs. 51-52.

${ }^{7}$ L. S. Vygotsky, Pensamiento y lenguaje, Buenos Aires, La Pléyade, 1977. 
adulto se entienden no porque los conceptos asociados a las palabras sean los mismos, sino porque las usan para referirse a las mismas cosas. En realidad, a pesar de que se cite a Frege en apoyo de la teoría intensional de los nombres propios, creemos que está más próximo a la teoría referencial que hemos tratado en el apartado anterior.

En cualquier caso, no parece que la linguística tenga que explicar el senti$d o$ de los nombres propios tal como aparece este concepto en la teoría de Frege. L. Hjemslev escribió que «la gramática [la lingüística, diríamos nosotros] tiene la bien definida tarea de explicar lo que desde el punto de vista del sistema es esencials ${ }^{72}$.

La teoría de B. Russell, que, según decíamos, ha extendido la denominación de teoría descriptiva, es, en nuestra opinión, más radical. Para él los llamados nombres propios son descripciones abreviadas, y los únicos nombres propios son los morfemas del tipo esto. Así nos dice que

lo que comúnmente se llaman nombres propios —por ejemplo, Sócrates-puede definirse, si estoy en lo cierto, en términos de cualidades y relaciones espacio-temporales, y esta definición constituye un verdadero análisis [...]. Si esto es correcto, los nombres propios, en el sentido ordinario, son engaños, implican una metafísica falsa ${ }^{73}$.

De esta manera se explica que el significado de los nombres propios sea semejante al significado de las descripciones definidas, pues ambas implican la existencia de una serie de características en el objeto designado que nos permiten su identificación. Parece claro, como señala Robert M. Martin ${ }^{74}$ que, en muchos casos, podemos reconocer el objeto designado por un nombre propio mediante datos que no son características del objeto. Así, dice que podemos reconocer la presencia de un caniche que se llama Max sólo por la presencia de su propietario. La opinión de Gardiner sobre la teoría de los nombres propios de Russell es digna de ser conocida: "Assuredly the most fantastic theory of proper names that has ever come to birth is that propounded by Bertrand Russell in a set o lectures subsequently published in a periodical» ${ }^{75}$.

En esta progresión ascendente de las definiciones conceptuales del nombre propio, nos referimos a la expuesta por $O$. Jespersen:

Utilizando la terminología de Mill, pero en contraste absoluto con su concepción, me atrevería a decir que los nombres propios (tal como se usan efectivamente) «connotan» el mayor número de propiedades.

\footnotetext{
72 L. Hjelmslev, La categoría de los casos, Madrid, Gredos, 1978, pág. 126.

${ }^{73}$ B. Russell, El conocimiento humano, Barcelona, Orbis, 1983, pág. 96.

${ }^{74}$ R. M. Martin, The Meaning..., pág. 163.

${ }^{75}$ Sir A. Gardiner, The Theory..., págs. 57-58.
} 
La primera vez que oímos el nombre de una persona o que lo leemos en un periódico, no es más que un simple nombre, pero, cuanto más lo oímos y lo vemos, más significa para nosotros. Reparemos también en la forma en que nos familiarizamos con una persona de una novela a medida que leemos. Pero lo mismo exactamente ocurre con un nombre común que es nuevo para nosotros [...].

Si los nombres propios tal como efectivamente los usamos no connotasen muchas propiedades, nos sería imposible comprender o explicar el fenómeno cotidiano de la conversión de los nombres propios en comunes» ${ }^{76}$.

Aunque Jespersen no hace mención de la cuestión, podemos suponer que los encuentros de los diferentes miembros de la comunidad linguística con un nombre determinado - Sócrates, por ejemplo- no son coincidentes y que, por lo tanto, lo que los nombres connotan varía de unos individuos a otros. En este sentido, la explicación de Jespersen de los nombres propios tiene los mismos inconvenientes que la ya mencionada de Frege y Russell. Esta variación del significado es para J. Algeo uno de los problemas de esta teoría, pues «the meaning of a name is made a wholly private matter ${ }^{77}$.

La connotación de la que habla Jespersen se puede identificar con nuestro conocimiento de la realidad, es decir, con nuestro conocimiento enciclopédico. $\mathrm{Y}$ en esto coincide con la explicación de los nombres propios que encontramos en U. Eco:

Por lo que se refiere a los nombres propios de personas, la solucion aparecerá más fundada a la luz del semema como enciclopedia. Si la representación del semema $\mathrm{X}$ asigna a una unidad cultural todas aquellas propiedades que, de forma concordante, se le atribuyen en una cultura determinada, nada está mejor descrito en todas sus particularidades que la unidad correspondiente a un nombre propio. Esto ocurre ante todo en el caso de nombres de personajes históricos: cualquier enciclopedia nos dice todo lo que es esencial para identificar la unidad cultural (Robespierre) [...].

Pero lo mismo podemos suponer de personajes no famosos (Juan Pérez), sobre el cual existe una descripción satisfactoria en la oficina del censo del municipio en el que resida ${ }^{78}$.

Aunque, aparentemente, la utilización del término enciclopedia parezca sacar el significado de los nombres propios del espacio de la mente y situarlo en una realidad más objetiva, como es el conocimiento de los objetos a los que se refieren, esta explicación no supera la crítica razonable de que el significado del

\footnotetext{
${ }^{76}$ O. Jespersen, La filosofía..., pág. 64.

77 J. Algeo, On defining..., pág. 66 .

${ }^{7 B}$ U. Eco, Tratado de semiótica general, Barcelona, Lumen, 1985, págs. 162-163. Una explicación semejante encontramos en U. Eco, Semiótica y filosofia del lenguaje, Barcelona, Lumen, 1990, pág. 159.
} 
nombre propio sería distinto para los diferentes usuarios, pues nuestro conocimiento de esas unidades culturales -Robespierre, por ejemplo- es diverso.

Pero quizás, en nuestra opinión, la mayor dificultad para aceptar la teoría conceptual del significado de los nombres propios, aunque no sólo para los nombres propios, es su asimilación a los nombres comunes. Hemos visto que U. Eco habla de semema, que Jespersen no diferencia los nombres propios de los comunes y que Russell les atribuye un contenido descriptivo. El carácter variable del significado, desde este punto de vista, no sólo se da en los nombres propios, también la intensión o connotación de un nombre común puede variar de un individuo a otro, aunque, como decía Vygotsky, la comunicación funcione, pues usamos las palabras para referirnos a cosas semejantes. La diferencia de significado o de función semántica entre los nombres propios y los sustantivos consiste en que estos últimos tienen una función semántica clasificadora de la realidad, es decir, establecen categorías; en cambio, los nombres propios, aunque admitiéramos que llevan asociada alguna característica del objeto - distinta para los distintos usuarios- no son signos categorizadores. Por lo tanto, la teoría conceptual del significado de los nombres propios, entendida como realidad mental o entendida como enciclopedia - realidad cultural- no nos parece válida para explicar la función semántica de esta clase de signos; en realidad, no nos parece válida para explicar la función semántica de ninguna categoría de signos, aunque no rechacemos la existencia de realidades mentales.

En otros casos se habla de la connotación de los nombres propios en un sentido diferente del visto hasta ahora. C. Kerbat-Orecchioni afirma que uno de los significados de los nombres propios consiste en que «evocan un sexo determinado, un origen geográfico y no otro, porque pueden ser cómicos o ridículos, vulgares $\mathrm{o}$ aristocráticos; porque pueden hacer recordar a un personaje histórico o literario [...]» ${ }^{79}$. Asimismo A. Lopez considera objetable el supuesto valor exclusivamente denotativo de los nombres propios: «Por ejemplo, Kathy e Iván clasifican inequívocamente a las personas de dicho nombre entre las nacidas a partir de los años sesenta o setenta, o entre los extranjeros, pues antes de dicha fecha estos nombres de origen foráneo eran impensables en español» ${ }^{80}$.

En nuestra opinión, los hechos señalados en las dos últimas citas no forman parte del significado de los nombres propios, usando el término significado de una manera pretendidamente técnica, como función semántica formalizada. La función semántica de Iván es la misma que la función semantica de Juan. Lo demás seguramente pertenece a nuestro conocimiento de la realidad y de los hábitos sociales.

${ }^{79}$ C. Kerbat-Orecchioni, La connotación, Buenos Aires, Hachette, 1983, pág. 193.

${ }^{80}$ A. López, Gramática..., pág. 100. 
Hay otras caracterizaciones de los nombres propios que difícilmente podrían incluirse en las dos corrientes que hemos comentado: algunas de ellas, porque pretenden asumir las diferentes definiciones propuestas considerándolas complementarias; otras, porque se sitúan claramente en el terreno de la pragmática.

Entre las primeras, podemos citar la de Marc Willmet ${ }^{81}$ que pretende establecer una especie de compromiso entre Mill, Russell y Kleiber. También podemos incluir aquí la de Jean Molino ${ }^{82}$, que distingue diferentes niveles de significación que recogen las diferentes definiciones propuestas.

Entre las segundas, podemos citar la explicación de Gilles Granger ${ }^{83}$, para quien la explicación del significado de los nombres propios en el diccionario y en la gramática no puede dar cuenta de su contenido, pues este depende de la enunciación. Ante esta propuesta, tenemos que considerar que, en todos los signos y construcciones que tienen función designativa, el referente depende siempre de las circunstancias de la enunciación; pero la función semántica de una construcción, como la mesa, o de un signo, como Juan, no puede ser el objeto que nombramos en que cada caso, sino el uso que hacemos de ellos y que es común a todos los casos de utilización. La pragmática, como estudio del sentido de los enunciados, no puede sustituir el estudio lingǘstico del significado de los signos y las construcciones, pues diferentes usos de Juan pueden nombrar diferentes individuos; pero lo usamos en todos los casos de la misma manera, es decir, con la misma función semántica. No podemos identificar el significado con el objeto que nombramos en cada caso, que sólo es identificable a partir de las circunstancias de la enunciación, de la misma ma ${ }^{+}$ nera que no podemos decir que el significado de un signo como esto es el objeto al que nos hayamos podido referir en un enunciado concreto.

\section{3. ¿LEXEMAS O MORFEMAS?}

Ya hemos expuesto nuestra preferencia por una clasificación bipartita de los signos en lexemas y morfemas. La hemos preferido a la clasificación, también bipartita, que distingue las palabras llenas de las palabras vacías. Entendemos que la función semántica de los lexemas es claramente distinta de la función semántica de los demás signos, incluidas las palabras gramaticales que suelen considerarse como palabras llenas. Por otra parte, creemos preferible hablar de clases de signos, frente a clases de palabras o partes de la oración o partes del discurso.

\footnotetext{
${ }^{81}$ M. Willmet, «Nom propre et ambiguité», en LFr. 92, 1991, págs. 113-135.

82 J. Molino, «Le nom...», pág. 16.

${ }^{83}$ G. Granger, «A quoi...?», págs. 27-28.
} 
Entendemos también que el criterio clasificador debe ser la función semántica de los signos, y debemos incluir en la misma categoría todos los signos que tengan la misma función semántica. La mayoría de las palabras que encontramos en el diccionario son categorizaciones de la realidad, pero no son categorías de la linguística como estudio del lenguaje. Nada hay en la forma material de los signos que les obligue a tener una $\mathrm{u}$ otra función: la función semántica de un signo sólo es el uso que hacemos de él.

Desde este punto de vista, incluimos en el léxico todos los signos que utilizamos para clasificar o categorizar la realidad — sea del tipo que sea, incluida la propia realidad lingüística, a la cual nos referimos con términos como palabra. Incluimos entre los morfemas todos los signos cuya función semántica no consiste en establecer categorías de la realidad. Las sucesivas subclases de signos que se pueden establecer en cada clase deberán compartir el rasgo asignado al conjunto y mostrarán alguna diferencia específica que sirva para establecer la diferencia entre género y especie. Así las sucesivas subclases de lexemas tendrán todas la característica atribuida a la clase más algún rasgo específico.

De la misma manera - una vez establecida la definición de los morfemas por medio de su rasgo característico, la función semántica no categorizadora de la realidad - procederemos al establecimiento de subclases, cada una de las cuales tendrá algún rasgo específico. $Y$ así continuaremos la clasificación hasta que no sea posible establecer más categorías lingüísticas. La repetida caracterización de los morfemas como conjuntos cerrados no dice nada de su función semántica. Si incluimos los numerales entre los morfemas, pues no son signos clasificadores, estaríamos no sólo ante un conjunto no cerrado, sino ante un conjunto ilimitado. Lo mismo ocurre si incluimos los nombres propios entre los deícticos, como es nuestra propuesta.

Para caracterizar la función semántica de los nombres propios y proceder a su inclusión en una categoría de morfemas, debemos observar cómo los usamos, pues son los hablantes los que fijan mediante el uso la función de los signos. En este sentido, creemos que continúa teniendo validez la propuesta clásica de que la descripción de la gramática se basa en el uso, y no al revés. Pero es evidente, como ha sido recogido en numerosos estudios, que los nombres propios los usamos de maneras diferentes: Aquí viene Juan, Aquí viene el Juan, Hay un Juan en mi clase, Hay más Juanes que Antonios, Este se llama Juan, entre otros usos.

Para identificar la función semántica de los nombres propios, como para identificar la función semántica de cualquier otra clase de signos, es preferible observar su uso cuando aparecen utilizados solos, sin artículo ni plural ni ningún otro complemento. Esto lo podemos hacer así sólo con los signos que tienen referencia autónoma; con los signos auxiliares sólo podemos observar su 
función semántica comprobando las modificaciones que producen, el rol que desempeñan, respecto a los signos a los que acompañan. Así la función semántica de suyo, por ejemplo, la podremos observar mejor en construcciones del tipo Este libro es suyo que en las del tipo Este libro es el suyo, pues, en este último caso, el artículo ha producido una modificación de su función semántica. Lo mismo ocurre con los nombres propios: para identificar la función semántica que desempeñan, debemos observarlos cuando aparecen solos, en su utilización «normal», no en su utilización metalingǘstica en frases del tipo Este se llama Juan o Juan es un nombre propio.

La función semántica que puedan tener los nombre propios utilizados en combinación sintáctica con otros signos que los modifiquen o determinen de alguna manera debe explicarse recuriendo al mecanismo sintáctico. Así podremos explicar los cambios de función semántica que puedan derivar de su combinación con el artículo, el plural, los numerales o con diferentes tipos de complementos, de la misma maniera que la función semántica que desempeñan los sustantivos, como subclase de lexemas, puede ser modificada o precisada de diferentes maneras mediante el mecanismo sintáctico; pero estas modificaciones o precisiones no forman parte de su caracterización como clase de signos. Pero hay que reconocer que estas modificaciones o determinaciones están condicionadas por la función semántica que como tal clase de signos tienen, pues es su función semántica la que explica sus posibilidades combinatorias. Así, por ejemplo, es la función semántica de los nombres propios, frente a la función semántica de los sustantivos, la que explica su comportamiento respecto al artículo.

Partiendo de las consideraciones expuestas, podemos dar como primera característica de la función semántica de los nombre propios su función designativa: son signos, morfemas, que utilizamos para nombrar identificando el referente designado. Pero su significado no puede ser el objeto designado en cada caso, que siempre dependerá de las circunstancias de la enunciación, sino su modo de significar, la forma en que los utilizamos para referimos a la realidad.

Nombrar la realidad de la que hablamos es una de las cosas que hacemos cuando utilizamos la lengua. Frecuentemente construimos los nombres mediante un lexema adscribiendo el objeto a una categoría. En otros casos, utilizamos signos que no aportan ninguna categorización del objeto designado. Los nombres propios pertenecen al grupo de los morfemas gramaticales (nominales gramaticales) que tienen capacidad designativa identificando el referente. Pertenecen al mismo grupo que los pronombres personales y demostrativos. Hay otros morfemas que también designan, pero no identifican el referente: son aquellos cuya referencia se basa en el significado gramatical de cantidad. Los que designan identificando el referente lo hacen mediante la deixis. 
En las páginas anteriores, ha aparecido reiteradamente la relación, o semejanza, de los nombres con los pronombres personales y demostrativos. Peirce, a pesar de la ambigüedad de su exposición, parecía decantarse por la inclusión de los nombres propios entre los Índices o Subíndices.

Tenemos, pues, un conjunto de nominales gramaticales deícticos que usamos para designar identificando el referente. Insistimos en que nada hay en los signos yo, este o Juan que los determine a tener esa función; tienen esa función simplemente porque los de una determinada manera.

Entre los décticos, se han asimilado con más frecuencia a los personales que a los demostrativos, quizás porque los nombres propios más prototípicos, más utilizados, son los nombres de persona. Pero, en nuestra opinión, su función designativa está más próxima a los demostrativos que a los personales. En primer lugar, porque todos los nombres propios designan un referente de tercera persona, lo mismo que los demostrativos; en segundo lugar, porque, aunque normalmente identifican por sí mismos el referente a partir de las circunstancias de la enunciación, a veces suelen llevar, como los demostrativos, algún tipo de especificación: así, frente a Dame aquel, podemos precisar la referencia afirmando Dame aquel de la esquina; y frente a He visto a Juan, podemos precisar la referencia de la manera que vemos en He visto a Juan el del quinto. No parece posible utilizar este tipo de determinaciones de la designación con los pronombres personales él o ella, por ejemplo. Parece, pues, que hay alguna diferencia en la función semántica, en la forma en que los usamos para nombrar, entre los pronombres personales y los nombres propios y demostrativos: los primeros identifican el referente designado de manera inequívoca a partir de las circunstancias de la enunciación, los segundos pueden necesitar especificaciones ulteriores que son aportadas mediante la combinatoria sintáctica.

Nos parece razonable considerar, por lo tanto, que los nombres propios son deícticos demostrativos particulares, o individuales, frente a los tradicionales demostrativos, que son generales o universales. Pero, según decíamos, entendemos que las convenciones que regulan el uso de los nombres propios son tan generales como las convenciones que regulan el uso de los demás demostrativos. La diferencia está en que esas convenciones generales han establecido que la mayoría de ellos, los nombres propios, sean usados par designar un referente particular, una especie de etiqueta; en cambio, esas mismas convenciones han establecido que otros, los llamados demostrativos, sean usados para designar cualquier referente. Al ser deícticos de carácter general, la designación, como no podría ser de otra manera, tiene que realizarse mediante la mostración del referente en la dimensión espacial o en la temporal.

Así pues, si nuestra interpretación y nuestra argumentación resultaran adecuadas, los nombres propios serían signos no clasificadores, pertenecientes a la 
clase de los morfemas que tienen función designativa, o nominales gramaticales; y, dentro de ellos, pertenecen a la subclase de los deícticos; por el modo de desempeñar la función designativa, están más próximos a los demostrativos que a los personales, de los cuales se diferencian porque son designadores particulares —designadores rígidos los llamó S. Kripke- frente al carácter universal de los demostrativos cuya función semántica se basa en la mostración temporal o espacial. Ch. S Peirce escribió que «un nombre propio, un pronombre personal demostrativo o un pronombre relativo, o la letra incluida en un diagrama, denotan lo que efectivamente denotan por una conexión real de su objeto» ${ }^{84}$. Parece, pues, que cada nombre propio tiene una conexión real con un referente particular y son, efectivamente, designadores rígidos.

\section{LA SINTAXIS DE LOS NOMBRES PROPIOS}

En nuestra opinión, uno de las hechos que ha oscurecido la explicación de la función semántica de los nombres propios como clase de signos ha sido que se han pretendido explicar todos los usos de los nombres propios a la hora de definir la categoría. Pero los nombres propios, según hemos apuntado, como todos los signos que tienen referencia autónoma, pueden entrar en combinaciones sintácticas que modifican y/o especifican su función semántica. Prueba de ello es la posición de J. Algeo, que rechaza las propuestas para definir los nombres propios como signos que tienen una referencia inherentemente definida: «The categories PROPE and DEFINTTE are not equivalent. Reinterpreting the traditional view of the uniqueness of proper names as a matter of definite reference will not account adequately for the diversity use of such names in ordinary language» 85 .

Nos parece razonable que, una vez definida la categoría con los criterios expuestos, los diferentes usos se expliquen en la sintaxis. Si la gramática de una lengua debe proceder a una clasificación de los signos y al estudio de las combinaciones que realizamos al hablar, corresponderá a la sintaxis la explicación de las diferentes funciones semánticas de las construcciones en las que aparezca un nombre propio, pues serán el resultado de la combinatoria sintáctica. Naturalmente, las posibilidades de combinación sintáctica de un signo están condicionadas por su función semántica. Por este motivo, el propio J. Algeo escribió que los criterios más destacables en la caracterización sintáctica de los nombres propios son: «Proper names have no plural. Proper names are used without articles. Proper names do not accept restrictive modifiers» ${ }^{86}$.

\footnotetext{
${ }^{84}$ Ch. S. Peirce, Obra..., pág. 265.

${ }^{85} \mathrm{~J}$. Algeo, On defining..., pág. 48.

86 Ibi., pág. 83.
} 
Esa no distinción, o confusión, entre la función semántica de la categoría y la función semántica de las construcciones en las que puede aparecer llevó también a Mary-Noëlle Gary-Prieur ${ }^{87}$ a rechazar que pudiera darse una interpretación única aplicable a todos los casos; y propuso distinguir tres modos de funcionamiento de los nombres propios: interpretación denominativa, interpretación identificadora e interpretación predicativa.

Las posibilidades de combinación de los nombres propios se podrían dividir en dos grandes grupos: su relación con morfemas auxiliares y su relación con signos o construcciones con referencia autónoma. Entre los primeros sólo tiene interés su relación con morfemas que funcionan como modificadores de función referencial (función semántica), como el plural, el artículo o los posesivos, pues su combinación con preposiciones y conjunciones es del mismo tipo que la que se produce con otros signos y no cambia la función semántica de los nombres propios. Cuando el nombre propio se combina con otros signos o construcciones que tienen referencia autơnoma, se producirá, como es normal, algún tipo de delimitación de la referencia, como en el ejemplo ya citado He visto a Juan el del quinto.

Una de las cuestiones más citadas respecto a los nombres propios es su combinación con el plural. E. Coseriu le dedicó un artículo ya en $1955^{88}$; y, en fechas recientes, aunque dedicado al estudio de los nombres propios en la lengua francesa, tenemos el trabajo ya citado de Mary-Noëlle Gary-Prieur), L'individu pluriel. Les noms propres et le nombre.

El morfema de plural es un cuantificador y, como tal, funciona como un modificador de la función referencial. Algunas gramáticas lo incluyen entre los actualizadores. Pero la modificación referencial que producen depende de la función semántica del signo al que se une. Así la diferencia de función semántica que se da entre camión, con una función semántica exclusivamente clasificadora o conceptualizadora, y camiones, con referencia genérica, se debe a la función del plural, como podemos comprobar en Había ruedas de camión frente a Había camiones. Cuando el plural se une a un nombre propio, cambia también su función semántica en el sentido de que ya no identifica el referente, como en Hay Antonios en mi clase. El resultado es el mismo que si usamos cualquier otro morfema de cantidad con un nombre propio, nos referimos a morfemas con referencia autónoma: Hay dos Antonios en mi clase, En este pueblo hay muchos Antonios. En estos casos, la única posibilidad de recuperar la función designativa con identificación del referente es recurrir al artículo: los Antonios de mi clase, los dos Antonios de mi clase. Así pues, los nombres propios en plural pueden tener dos funciones semánticas: referencia plural no

${ }^{87}$ Mary-Noëlle Gary-Prieur, Grammaire.... págs. 58-61.

${ }^{88}$ Recogido en E. Coseriu, Teoría del lenguaje..., págs. 261-268. 
identificadora; referencia plural identificadora, si van acompañados del artículo o de otro morfema deíctico identificador. En estos casos el artículo no es un elemento enfático o innecesario. Pero, si nuestra explicación resultara razonable, no se trataría de que los nombres propios no tengan plural, sino de que el plural cambia la función semántica de los nombres propios, su modo de referencia.

En otros casos, cuando no se produce la alternancia singular / plural como en los casos vistos, y el nombre propio sólo se usa en plural, como en Canarias, la forma del plural es parte del nombre propio.

Otra de las características sintácticas atribuidas a los nombres propios es que no se combinan con el artículo. Así lo hemos recogido en páginas anteriores y así suele aparecer en nuestras gramáticas. En las últimas publicadas sobre el castellano, encontramos explicaciones que inciden en su comportamiento especial con el artículo.

E. Alarcos afirma que

los nombres propios tienen un comportamiento especial respecto al artículo. Unos lo llevan siempre, otros lo rechazan. Y, en fin, algunos hacen alternar libremente su presencia o su ausencia. Sin embargo, en los tres casos la referencia del nombre propio es la misma: cumplen la identificación del objeto designado en el campo de situación de los hablantes. Así tenemos sin artículo Europa, Madrid; con artículo los Pirineos, el Duero, la Mancha; con alternancia Coruña-la Coruña, China-la China, Perí-el Perú ${ }^{89}$.

A. di Tulio señala que «tanto sustantivos propios como pronombres constituyen la expresión máxima del sintagma: rechazan, en su uso habitual, la presencia de especificativos, modificadores restrictivos y complementos» ${ }^{90}$.

$\mathrm{Y}$ en F. Marcos, F. J. Satorre y M., L. Viejo, leemos que «los nombres propios suelen tener un comportamiento gramatical diferente de los sustantivos, sobre todo en su combinación con el artículo y con el morfema de plural» ${ }^{91}$.

Comentaremos brevemente algunos de los usos más característicos de la combinación del nombre propio con el artículo. Creemos que la función semántica del artículo es siempre la misma, aunque en algunos casos puede resultar enfático: el artículo atribuye función semántica designativa identificadora a cualquier signo o construcción a la que se antepone.

Ya hemos visto que, cuando el nombre propio se usa en plural, es necesaria la presencia del artículo para recuperar la identificación del referente. En otros casos, la pluralidad puede estar implícita. España es un nombre propio que identifica un referente habitual; pero ese referente puede ser visto como

\footnotetext{
E. Alarcos, Gramática..., pág.. 68.

90 A. di Tullio, Manual.., pág. 148.

${ }^{91}$ F. Marcos, F. J. Satorre y M. ${ }^{a}$ L. Viejo, Gramática..., pág. 120.
} 
una pluralidad de referentes: la España seca, la España húmeda, la España de los Austrias, la España de charanga y pandereta. En estos casos, se ha generalizado la utilización del artículo para la identificación del referente, pues realmente es visto como un componente de una pluralidad. Esta es la explicación que encontramos en Mary-Noëlle Gary-Prieur ${ }^{92}$. Y, aunque su estudio se basa en la lengua francesa, entendemos que su explicación es adecuada y que esta utilización de los nombres propios con el artículo en español se produce de manera semejante.

Pero parece que sólo es necesario cuando el referente único de un nombre propio es visto como una pluralidad. Así decimos que Vivimos en Córdoba capital frente a No nos gusta la Córdoba de los barrios o La Córdoba que yo conoct. Quizás en los casos del tipo Vivimos en Córdoba capital o Sólo conocemos Córdoba provincia, el referente designado en cada caso no es visto como una pluralidad de referentes dentro de un referente único, sino como dos referentes distintos. No es fácil decidir en todos los casos. Los signos y su gramática nos ofrecen sistemas de representación de la realidad con los que los hablantes «juegan» de manera parecida; pero de ningún modo podemos suponer que las mismas formas responden siempre a la misma realidad ontológica; las mismas formas son simplemente el mismo mecanismo de representación. Una vez definida la función semántica de un signo o de una combinación de signos, debemos suponer que siempre que el hablante los utiliza, está recurriendo a las mismas formas de representación. Así, tomando un ejemplo del léxico, todos los usos que los hablantes hagan de la palabra silla son muestra de la utilización de un mismo elemento de representación de la realidad, sea cual sea la realidad ontológica a la que se refiera. De la misma manera, podemos suponer que siempre que los hablantes usan construcciones del tipo la España húmeda estamos ante un mismo esquema de representación, aunque la realidad ontológica referida en cada caso no sea idéntica. El estudio de los diferentes tipos de realidad representada sólo nos interesa en la medida en que a cada uno de ellos corresponda un tipo diferente de representación.

En otros casos se dice - así lo hemos visto en E. Alarcos- que el artículo siempre acompaña al nombre propio. Esto es lo que Mary-Noëlle GaryPrieur ${ }^{93}$ llama 'combinación lexicalizada'. Según nuestro punto de vista, ya que nos inclinamos por no incluir los nombres propios en el léxico, esa caracterización como combinación lexicalizada no sería adecuada; sería preferible hablar de construcción gramaticalizada, mediante la cual queremos decir que los dos signos que aparecen ya no son resultado de la combinatoria sintáctica, sino que funcionan como una sola unidad gramatical.

${ }^{92}$ Mary-Noëlle Gary-Prieur, Grammaire..., pág. 108.

${ }^{93} \mathrm{Ibi}$., pág. 99. 
Nuestras gramáticas señalan también la utilización del artículo con nombres propios en construcciones del tipo Aquí viene el Juan o El Carlos ya se ha marchado, que califican de coloquial o vulgar. Esta explicación pone de relieve, efectivamente, el nivel sociolinguístico en el que suele aparecer. En una perspectiva teórica, los distintos tipos de variedades sociolingüísticas tienen la misma función semántica, pues, de lo contrario, no serían tales variables. En este caso estamos ante variaciones diastráticas. Esta explicación es correcta, pero quizá sea incompleta. El artículo no es necesario para la función designativa que el nombre propio desempeña; la utilización de un elemento no necesario, como repeticiones o elevaciones de la voz por encima del tono normal, tienen una valor enfático. De esta manera, la utilización de el Carlos / Carlos en ejemplos como el citado sería una muestra de la función expresiva del lenguaje. Probablemente esta sea la causa de que su uso sea especialmente frecuente en niveles sociolingüísticos en los que la emotividad y la expresividad tienen mayor presencia. Entendemos, además, que la presencia enfática del artículo, que es un nominalizador, ante un nombre propio, que por sí mismo tiene función designativa, se da sobre todo para designar individuos del círculo próximo a los interlocutores, es decir, que, en enunciados como el Carlos se ha marchado, es probable que el individuo designado pertenezca al grupo en el que se incluyen los interlocutores.

Hay otros casos, menos frecuentes, en los que también aparece el artículo con el nombre propio. Tradicionalmente, este uso del artículo se justifica en nuestras gramáticas por la necesidad de marcar el sexo o género gramatical del referente, como en la Guerrero o la Pérez. Estamos ante signos que linguísticamente son nombres propios, aunque jurídicamente puedan ser considerados apellidos, y no aportan ninguna información sobre el sexo de los individuos designados. En estos casos, el artículo sería estrictamente innecesario en su función nominalizadora; pero no lo sería en el sentido apuntado. Entendemos que se trata de usos del artículo semejantes a los que se producen ante el relativo que sin antecedente: es necesaria la presencia del artículo para marcar el género gramatical del referente designado por el relativo: el / la que llamó ayer.

Quizás, si nuestra explicación resulta adecuada, esta podría ser también la explicación de la presencia de otro nominalizador que, de manera más o menos esporádica, aparece también con los nombres propios: nos referimos a los posesivos. En Mañana viene mi Juan, enunciado por una madre en una situación determinada, se justificaría no porque sea necesario el posesivo para la función designativa del nombre propio Juan, sino porque el hablante quiere, o entiende que es necesario, manifestar la relación con las personas gramaticales que expresan el posesivos $m i$. 
La tercera característica que se suele atribuir a los nombres propios, según hemos expuesto, es que no llevan modificadores restrictivos. A. López García afirma que

en el terreno sintáctico, una de las propiedades más significativas del nombre propio, que está en relación directa con su rechazo de la indeterminación, es su incapacidad para recibir la incidencia de sustantivos apositivos especificativos o de cláusulas relativas restrictivas ${ }^{94}$.

Este tipo de relación sintáctica, o de combinatoria sintáctica, es diferente de la que se comprueba en el caso del artículo o del plural: los signos que se añaden al nombre propio no cambian su modo de referencia, su función semántica, sino que la delimitan, la determinan de alguna manera. Esta es la función que aparece en expresiones del tipo Córdoba ciudad o la España de charanga y pandereta. También esta es la función del complemento que acompaña al nombre propio en construcciones del tipo Juan el del quinto. Parece que, razonablemente, podemos decir que con frecuencia el nombre propio es suficiente para identificar el objeto designado a partir de las circunstancias de la enunciación; pero, según hemos expuesto y lo hemos considerado el rasgo característico para no incluirlos entre los deícticos personales, a veces necesitan algún tipo de especificación que determine la referencia. Esto mismo es lo que ocurre cuando nos referimos a un individuo utilizando el nombre y los apellidos: Juan Ruiz Pérez es una construcción en la que cada uno de los apellidos funciona lingüísticamente como un nominal que determina el objeto designado por el nominal o los nominales que le preceden.

El hecho de que este tipo de delimitaciones de la referencia con los nombres propios sea menos frecuente que con otras construcciones designativas no cambia la función semántica de la construcción ni la relación entre sus componentes. La mayor o menor frecuencia de un tipo de construcción no es un dato para caracterizar su función; de la misma manera que un objeto directo tiene la misma relación semántica con el verbo, ya sea un verbo normalmente transitivo o sea un verbo raramente utilizado como transitivo.

$\mathrm{La}$ información aportada por los elementos que delimitan la referencia del nombre propio depende de la función semántica del complemento: así, en Córdoba ciudad, la información semántica aportada por el determinante es de carácter léxico, clasificador; mientras que en Juan Pérez la información semántica aportada por el determinante es de carácter designativo, pues Pérez es también un nombre propio, es otra forma de designar el referente señalado mediante Juan.

94 A. López, «Lo propio...», pág. 39. 
A modo de conclusión, entendemos, pues, que los nombres propios no pertenecen al léxico, sino que son nominales gramaticales deícticos, como los demostrativos; pero son deícticos particulares, designadores rígidos. Esta caracterización se basa en su utilización lingǘstica, no en su utilización metalinguística. Cualquier otra función semántica diferente de la que como tal clase de signos tienen hay que explicarla por la combinatoria sintáctica en la que aparecen, y ya no es la función semántica del nombre propio, sino la función semántica de las construcciones en las que aparece un nombre propio: no son características de la categoría sino de las construcciones en que se inserta la categoría. 